\title{
Impacts of Contracted Endodontic Cavities on Instrumentation Efficacy and Biomechanical Responses in Maxillary Molars
}

by

\author{
Brent Andrew Moore
}

A thesis submitted in conformity with the requirements for the degree of Master of Science Graduate Department of Dentistry University of Toronto

(C) Copyright by Brent Andrew Moore 2016 


\title{
Impacts of Contracted Endodontic Cavities on Instrumentation Efficacy and Biomechanical Responses in Maxillary Molars
}

\author{
Brent Andrew Moore \\ Master of Science \\ Graduate Department of Dentistry \\ University of Toronto \\ 2016
}

\section{Abstract}

This study assessed impacts of contracted (CEC) and traditional (TEC) cavities on instrumentation efficacy and biomechanical responses in maxillary molars. Eighteen extracted intact maxillary molars were imaged with micro-CT and accessed through CEC or TEC ( $\mathrm{n}=9 /$ group). Canals were instrumented, re-imaged and proportion of modified canal wall (MCW) determined. Another 28 molars ( $\mathrm{n}=14$ /group) with strain gauges were subjected to load cycles and microstrain recorded before access and after cavity restoration. These 28 molars and additional 11 intact molars were fatigued and loaded to failure. Data were analyzed with Wilcoxon rank sum and Kruskal-Wallis tests. Mean proportion MCW did not differ significantly

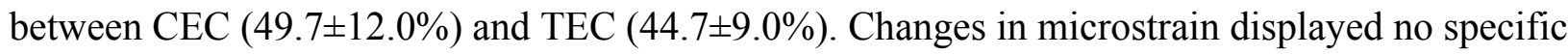
pattern in both groups. Mean load-at-failure for CEC $(1703 \pm 558 \mathrm{~N})$ did not differ significantly from TEC $(1384 \pm 377 \mathrm{~N})$; both were lower $(\mathrm{p}<0.005)$ than intact molars $(2457 \pm 941 \mathrm{~N})$. CEC did not appear to impact instrumentation efficacy and biomechanical responses compared to TEC. 


\section{Acknowledgments}

I would like to thank Dr. Shimon Friedman for his guidance, determination and tireless assistance in the preparation of this manuscript in addition to the extensive preparation for oral presentations. I would further like to acknowledge the generous contributions by Dr. Thuan Dao and Dr. Anil Kishen and I am grateful for their support during this research. In addition, Dr. Kostas Verdelis of the University of Pittsburgh was instrumental to the research with his expertise in microCT interpretation and I am thankful for his collaboration.

It was a privilege to study in the graduate endodontics master's program at the University of Toronto. It was an intense and rewarding experience and I feel honored to join the alumni. I would like to acknowledge the sacrifices endured by my wife Izumi and daughter Mirei while I pursued my education and I am grateful for their support. 


\section{Table of Contents}

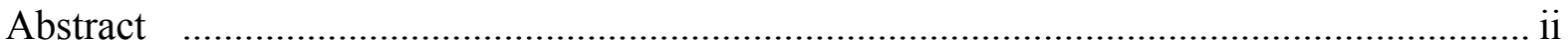

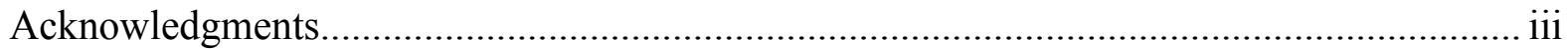

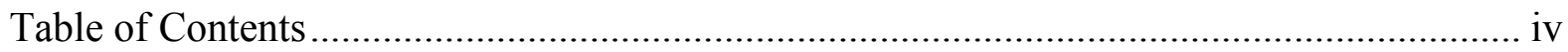

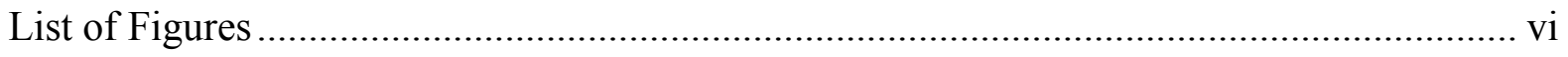

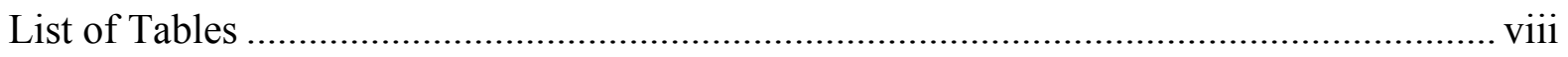

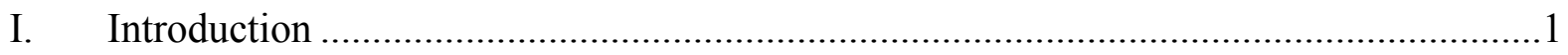

1. Minimally Invasive Health Care .....................................................................

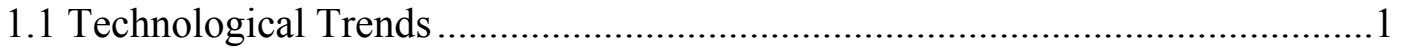

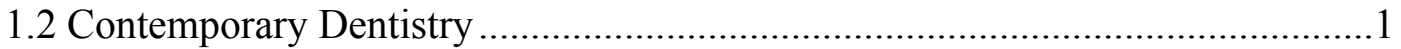

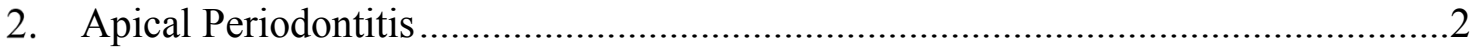

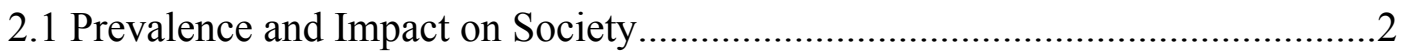

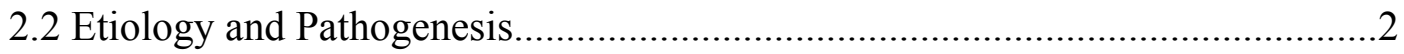

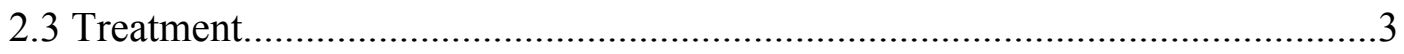

3. Outcomes of Endodontically Treated Teeth..........................................................

3.1 Healing of Apical Periodontitis ......................................................................

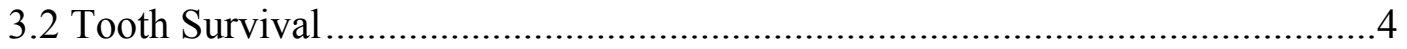

3.3 Epidemiology of Tooth Fracture ………………..............................................

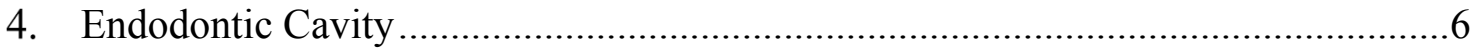

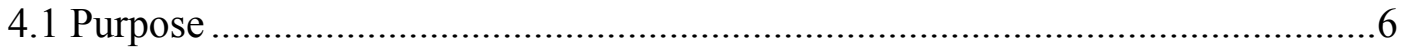

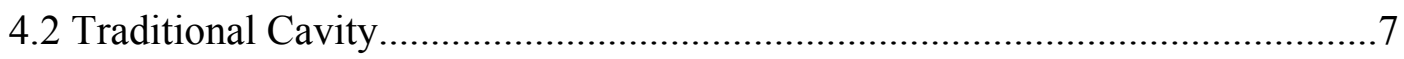

4.3 Contracted Cavity ....................................................................................

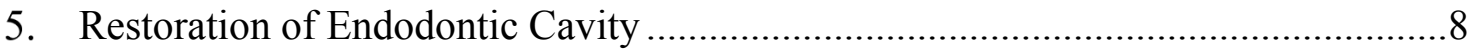

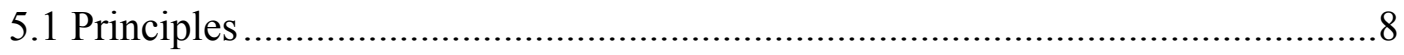




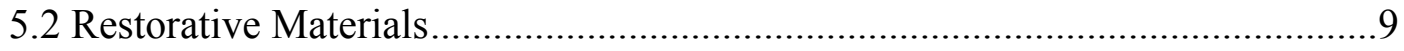

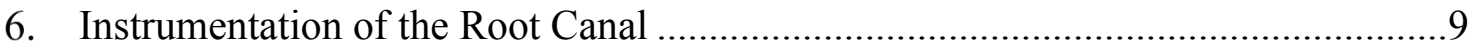

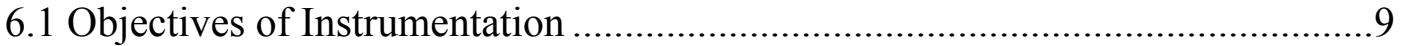

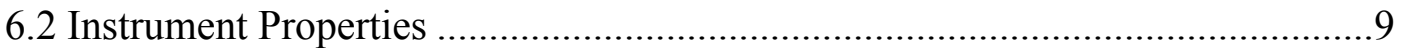

7. Micro-Computed Tomography.....................................................................10

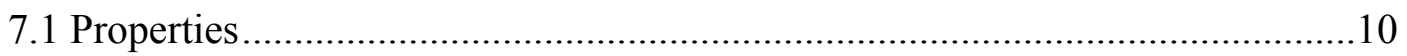

7.2 Applications in Endodontic Research …………………..............................10

7.3 Assessment of Root Canal Instrumentation Efficacy......................................10

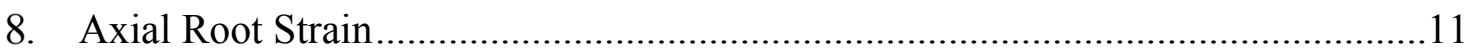

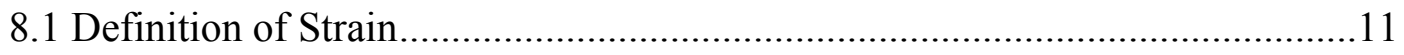

8.2 Application of Strain Measurements in Teeth....................................................11

9. Fracture Strength of Root Filled Teeth..................................................................12

9.1 Structural Properties of Teeth...................................................................12

9.2 Testing Fracture Strength of Teeth..................................................................13

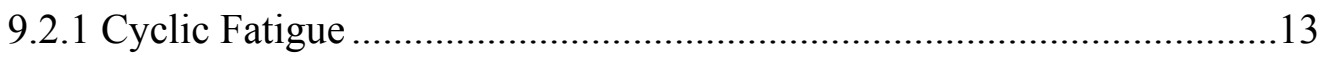

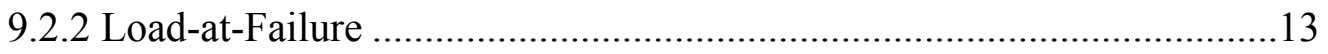

II. Objectives and Hypotheses......................................................................................

III. Article Submitted for Publication............................................................................

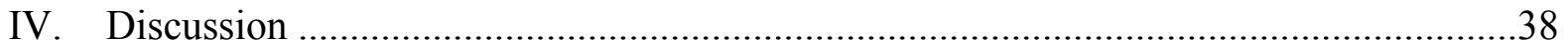

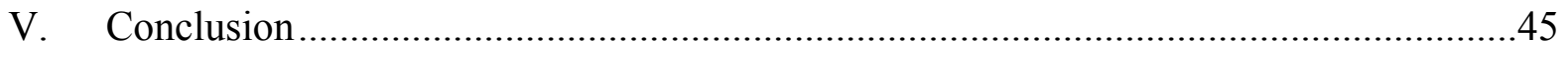

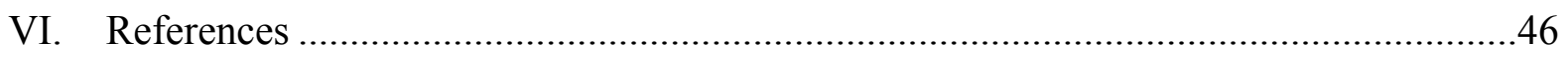

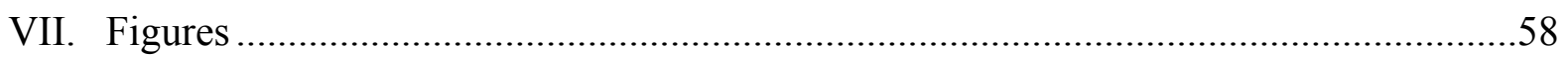

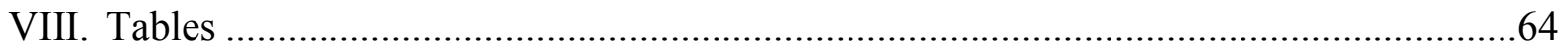




\section{List of Figures}

Fig. 1. The two access cavity designs used in this study. A. Contracted (CEC). B. Traditional (TEC).

Fig. 2. 3D reconstructed super-imposed micro-CT images of instrumented (yellow) and original root canals (red) of maxillary molars with Left: contracted (CEC) and Right: traditional (TEC) access. Yellow areas represent modified canal walls.

Fig. 3. Axial microstrain measured at mesio-buccal and palatal cervical root surfaces of a maxillary molar under simulated physiologic loads (50-150 N) in the Instron Universal Testing machine. Measurements were obtained before access (pre-op) and after contracted (CEC) access, canal instrumentation and bonded composite resin restoration (post-op). While the pre- and postop measurements at the palatal surface were similar, the measurements at the mesio-buccal surface changed from compressive microstrain pre-op, to tensile microstrain post-op.

Fig. 4. Median values of relative stiffness measured at mesio-buccal and palatal cervical surfaces of maxillary molars with restored contracted (CEC) or traditional (TEC) access, under simulated physiologic loads (50-150 N) in the Instron Universal Testing machine.

Fig. 5. Examples of load-at-failure recorded in restored maxillary molars with A. contracted (CEC) cavity and B. traditional (TEC) cavity, under compressive load preceded by 1 million cycles of fatiguing loads in the Instron Universal Testing machine.

Fig. 6. Mean load-at-failure in maxillary molars, intact (control) or with restored contracted (CEC) or traditional (TEC) access, under compressive load preceded by 1 million cycles of fatiguing loads in the Instron Universal Testing machine. 
Fig. 7. Examples of fractured maxillary molars with A. contracted (CEC) and B. traditional (TEC) cavity. 


\section{List of Tables}

Table 1. Modified Canal Wall (MCW) after instrumentation in maxillary molars performed through contracted (CEC) or traditional (TEC) access, assessed by micro-CT. MCW is expressed as proportion of the total canal wall area; mean and standard deviation values presented by coronal and apical halves of the three roots.

Table 2. Mean axial microstrain in maxillary molars with contracted cavity (CEC) and traditional cavity (TEC), measured at mesio-buccal and palatal root surfaces under simulated physiologic loads $(50-150 \mathrm{~N})$ in the Instron Universal Testing machine. Measurements were obtained before access (pre-op) and after endodontic cavity, canal instrumentation and bonded composite resin restoration (post-op).

Table 3. Load-at-failure values for maxillary molars with contracted cavity (CEC), traditional cavity (TEC) and controls (intact) under compressive load preceded by 1 million cycles of fatiguing loads in the Instron Universal Testing machine.

Table 4. Selected diameters of V-Taper2H rotary instruments in comparison to commonly used instruments with constant taper. 


\section{Introduction}

\section{Minimally Invasive Health Care}

\subsection{Technological Trends}

Health care continues to evolve, fostered by scientific research and technological advances $(1,2)$. Such evolution has led to improved understanding of disease in addition to revisions in clinical interventions and, more specifically, less invasive treatment procedures $(1,2)$. Such minimally invasive interventions were developed in part because of the morbidity and overall burden caused by traditional, more invasive procedures (1). Current evidence using minimally invasive techniques for certain medical interventions suggests improved short-term outcomes, such as decreased morbidity, and similar long-term disease outcomes compared to traditional techniques $(3,4)$. Minimally-invasive interventions $(1-6)$, highlighting minimal injury and preservation of natural tissues, require successful intersection of three essential elements (6): (i) specific benefits that outweigh potential risks, (ii) advanced technologies and (iii) adaptation of skills by clinicians.

\subsection{Contemporary Dentistry}

Alongside health care in general, scientific and technological advances in dentistry have similarly promoted a trend towards minimally invasive treatment (5). GV Black established the concepts of traditional operative dentistry, including design of cavities, at the turn of the $20^{\text {th }}$ century (7). Many of these principles endure today; however, with a greater selection of instruments, devices and restorative materials, modern cavity preparation designs have progressed away from principles such as "extension for prevention" in which healthy tooth structure is sacrificed to prevent future disease (7). Advances in dentistry have changed the understanding of oral diseases and treatment philosophies $(5,8)$, leading clinicians to apply 
minimally invasive techniques for operative dentistry with the understanding that such measures ultimately benefit patient-centered outcomes (8).

Likewise, in endodontics pioneering clinicians have developed alternative approaches with the aim to achieve treatment goals while preserving healthy tooth structure $(6,9-11)$. Even though selective studies suggest better outcomes result on average for teeth with greater remaining tooth structure $(12,13)$, the minimally invasive trend is not yet supported by high levels of scientific evidence $(5,6,9-11)$.

\section{Apical Periodontitis}

\subsection{Prevalence and Impact on Society}

According to the American Association of Endodontists, it is estimated that over 15 million root canal treatments are performed annually in the United States (14). Studies have reported the prevalence of apical periodontitis, defined as an apical rarefaction on a periapical radiograph, is approximately $5 \%(15,16)$ while the prevalence of root canal treatment was nearly $10 \%$ of all teeth. Furthermore, $36 \%$ of endodontically treated teeth showed radiographic signs of apical periodontitis (16).

\subsection{Etiology and Pathogenesis}

Apical periodontitis is a disease involving microbial infection of a tooth's root canal system and the subsequent host inflammatory immune response $(17,18)$. The symptoms accompanying the inflammatory process vary but may include moderate to severe pain, swelling and pain to biting or percussion (19). The infection incites innate and adaptive immune responses causing a 
complex cascade of inflammatory chemotactic signaling to attract immuno-competent cells, commonly leading to disruption of normal periapical tissues and resorption of contiguous alveolar bone $(18,20)$.

The host response is often effective in limiting the spread of infection from the tooth to other areas of the body (20). However, the host's immune system is unable to eradicate the source of the infection inside the root canal system $(17,20)$. Microbes invading the root canal system develop in a compound ecological form referred to as biofilm, which lines the root canal walls and infiltrates the dentinal tubules (21-23).

\subsection{Treatment}

To retain a tooth with intra-canal infection and apical periodontitis, it is treated primarily by chemo-mechanical debridement and disinfection (24). Access to the root canal system is accomplished through the coronal tooth structure via the endodontic cavity $(6,10,25)$. Endodontic instruments are used to remove the infected pulp, adherent biofilm and infected intra-canal dentin throughout the canal to its terminus (24-27). The microbial load is further reduced using chelating and disinfecting irrigants $(24,28)$. Following disinfection, the canal lumen is filled to entomb residual microbes and prevent any further ingress (29). The endodontic cavity and coronal tooth structure is then restored definitively, to prevent microbial ingress and to restore function (30-32). 


\section{Outcomes in Endodontically Treated Teeth}

\subsection{Healing of Apical Periodontitis}

Patients with teeth affected by apical periodontitis may elect to preserve these teeth with endodontic treatment $(16,33,34)$, which aims to retain teeth in health and in function for the long term (35-39). Treatment in accordance with the standard of care is expected to yield a favorable healing prognosis (35-39). Current best evidence suggests that complete radiographic healing of apical periodontitis occurs in approximately $83 \%$ of teeth after initial treatment, and that over $90 \%$ of teeth remain free of signs of apical periodontitis when it is not detected pre-operatively (35-39). Healing has conventionally been evaluated radiographically $(39,40)$ and clinically, although assessments of discomfort may be subjective (38).

\subsection{Tooth Survival}

While survival of the endodontically treated tooth disregards the periapical status, it may represent a more patient-centered (and functional) outcome. Studies have shown high survival rates of endodontically treated teeth, in the range of 80 to $95 \%$ for 4 to 10 years $(35,36,41)$. Several factors implicated in decreased survival include increased loss of dentin (12), lack of extra-coronal restoration $(36,42)$, greater number of missing teeth or fewer proximal contacts $(43,44)$, and tooth type - mandibular molars in particular (42-44). Loss of dentin associated with caries and operative procedures is a risk factor for fracture $(12,13,36,45,46)$; therefore, endodontic treatment approaches have been explored that emphasize tooth structure preservation with the aim to extend the longevity of treated teeth $(6,9-11,46)$. 


\subsection{Epidemiology of Tooth fracture}

Estimating incidence or prevalence of tooth fracture is fraught with challenges $(45,47-49)$.

Tooth fractures vary in location and extent but studies may not distinguish between vertical root fractures originating in the root and crown, or crown-root fractures originating in the coronal portion of the tooth (37). Often teeth with cuspal fractures are restorable, although crown-root fractures may only be restored in conjunction with other procedures, such as crown lengthening (50). Teeth with incomplete tooth fracture may remain asymptomatic or they may become symptomatic and require root canal treatment $(45,48,51)$ while others, especially with subgingival crack extension, are non-restorable and require extraction $(45,48,51)$.

The proportion of teeth that are lost to fracture may be estimated from longitudinal survival studies. A 10-year survival study reported a 7.2\% incidence of root fracture. Among the possible reasons for endodontically treated teeth requiring extraction, between 29 to $36 \%$ were attributed to fracture $(36,37,41)$. Specific studies have implicated loss of tooth structure as a predominant feature in teeth lost to fracture $(12,45)$.

\section{Endodontic Cavity}

\subsection{Purpose}

Access to root canals for endodontic treatment is via the endodontic cavity. The endodontic cavity thus enables identification of root canals, insertion of instruments, delivery of disinfecting irrigants and placement of the definitive root filling (25). Historically, endodontic cavity designs 
had been influenced by lack of powerful magnification and illumination, as well as limitations of available instruments $(25,52)$.

\subsection{Traditional Cavity}

Traditional endodontic cavity (TEC) guidelines were developed before the dental operating microscope was available and when root canal treatment was accomplished using relatively stiff stainless steel hand files $(25,52-57)$. Inadequate magnification obligated cavity outlines extending as straight projections from the canal orifices, to provide "convenience form" for the treatment procedures that follow $(25,52-54)$. Limitations of the instruments frequently led to treatment complications such as instrument breakage $(58)$, ledge creation $(56,57,59)$ canal straightening $(55,60,61)$ and perforations $(55,57)$.

TEC guidelines have persisted with the introduction of rotary nickel-titanium (NiTi) instruments and have remained unchanged despite many technological advances (Fig. 1B). These guidelines emphasize straight-line pathways for instruments to the apical one-third of the root (52) (Fig. 2), to enhance instrumentation efficacy and to prevent procedural errors, as previously described (52,54-56). Consequently, TEC guidelines involve removal of pericervical dentin (9-11,52-54), defined as the dentin $4 \mathrm{~mm}$ above and $6 \mathrm{~mm}$ below the alveolar crest (9). Such removal of tooth structure can influence the biomechanical responses of teeth $(46,62-67)$. Indeed, fracture strength in particular was significantly decreased in mandibular premolars and molars with TEC (46) due to excessive removal of dentin volume (46). 


\subsection{Contracted Cavity}

Contracted endodontic cavity (CEC) designs are intended to preserve tooth structure to maintain fracture strength of treated teeth $(6,9-11,46,68)$ (Fig. 1A), in line with modern dentistry's increasing focus on minimally-invasive interventions (5). These cavities forego complete unroofing of the pulp chamber to create orifice-directed pathways and sacrifice occlusal tooth structure to preserve pericervical dentin (9) (Fig. 2).

While CEC designs are restrictive and do not provide "convenience form", their use is enabled by technological advances. Endodontic specialists are increasingly using cone-beam computed tomography as well as enhanced magnification and illumination with the dental operating microscope. Use of these technologies has led to treatment approaches whereby identification and access to root canal anatomy is possible through smaller endodontic cavities. In addition, former concerns about stress on rotary instruments have been diminished using heat-treated (also referred to as controlled-memory) rotary nickel titanium instruments. These novel instruments have extreme flexibility in addition to increased resistance to cyclic fatigue (69-71), thus decreasing the risk of instrument fracture (69-71).

\section{Restoration of Endodontic Cavity}

\subsection{Principles}

Evidence suggests that adequate definitive restoration of endodontically treated teeth is a determinant of treatment outcomes $(32,36,44)$. In posterior teeth, or teeth with more extensive loss of tooth structure, an extra-coronal restoration (onlay or crown) is recommended and a post may be indicated $(31,32,72)$. Regardless of whether the treated tooth will receive extra-coronal 
coverage, the endodontic cavity requires restoration to prevent reinfection or tooth fracture (3032). The predominant restorative materials used to restore endodontic cavities include silver amalgam and composite resin $(30,32)$.

\subsection{Restorative Materials}

The materials selected for restoration of the endodontic cavity impact the physical properties of the restored tooth (68). Mandibular molars with Class I cavities restored with amalgam exhibited significantly lower fracture strengths $(73,74)$. Condensed into cavities, macro-mechanical retention is required for amalgam using convergent preparations and features such as slots and grooves (7). Amalgam is resistant to compressive forces with an elastic modulus of approximately 16 to $20 \mathrm{GPa}$ (75), which is similar to dentin at an average $18.6 \mathrm{GPa}(76)$, although amalgam is relatively weak under tension. Some other limitations of amalgam include setting time (75), non-esthetic color and potential staining (77), in addition to concerns regarding mercury toxicity (78). Despite a successful history, amalgam is increasingly being eschewed for composite resin (79).

Composite resin is an alternative dental restorative material used since the 1980's. Continued development over time has led to improved material properties (75) and adhesive restorative materials have transformed previously established standards $(5,7)$. Furthermore, modern composite resins have improved esthetic outcomes achieved with restorations (79). While variation exists according to manufacturer, the elastic modulus is slightly below that of dentin, ranging from 10 to $20 \mathrm{GPa}(80,81)$. Composite resins adhere to tooth structure using micromechanical retention of resin tags in "etched" enamel rods and in the hybridized layer of dentin (82). In the short term, bonded composite resin restorations of the endodontic cavity may 
partially or totally reverse the reduction in fracture strength imparted by the endodontic cavity $(46,65,83-86)$. However, the long-term stability of dentin bonding is subject to degradation (87).

\section{Instrumentation of the Root Canal}

\subsection{Objectives of Instrumentation}

Mechanical instrumentation is currently used in root canal treatment to remove pulp and infected tissues and to create space allowing the introduction of irrigants $(24,26,27)$. There is no consensus as to optimal technique or minimum increase in canal dimensions. Most agree disinfection is an important element of successful root canal treatment, although instrumentation must not be excessive such that it compromises the structural properties of the treated tooth (9). Technological advances and refined metallurgy permit new approaches that may improve canal wall debridement and minimize iatrogenic damage to the root dentin $(57,69-71,88)$.

\subsection{Instrument Properties}

Endodontic instruments commonly used are typically made with stainless steel or NiTi. Novel heat-treated NiTi instruments have improved properties in terms of flexibility and increased resistance to cyclic fatigue $(69,71)$. These instruments are available in different sizes and shapes. While hand files are regularly $2 \%$ fixed taper, rotary instruments may have fixed tapers (eg. $4 \%$, $6 \%$ ), or variable progressive or regressive tapers. More recently, smaller and regressive tapers

(Table 4) have become favored among clinicians using minimally invasive root canal treatments to avoid excessive removal of root and pericervical dentin (9). 


\section{Micro-Computed Tomography}

\subsection{Properties}

Micro-computed tomography (micro-CT) is a radiographic imaging technique used for in-vitro study, not suitable for clinical use due to the increased doses of radiation and time required for scans (89-92). Depending on the resolution and voxel size used, micro-CT produces highresolution three-dimensional scans that are analyzed in desired cross-sections with viewing software (89-92).

\subsection{Applications in Endodontic Research}

Micro-CT permits non-destructive evaluation of teeth. Endodontic research using micro-CT focused initially on root canal anatomy and morphological studies (93). More recently, using scans with increased resolution before and after different interventions allowed threedimensional examination of changes in tooth structure. Computer algorithms assist in calculation of properties such as radius of curvature, degree of canal straightening or transportation, volume of dentin removed and proportion of modified canal wall surface (MCW) $(46,89-92,94)$.

\subsection{Assessment of Root Canal Instrumentation Efficacy}

Efficacy of root canal instrumentation has been assessed using varying methods such as scanning electron microscope (SEM) (95), the split-tooth model (96) and micro-CT imaging (89). Each method is associated with specific strengths and weaknesses. Micro-CT serves as the reference standard when investigating MCW, a surrogate of instrumentation efficacy, since it permits nondestructive analysis at different stages and provides high-resolution, three-dimensional images 
for comparison (46,89-91). Using pre- and post-intervention scans, computer algorithms calculate the dentin voxels changed from intervention and report the MCW (Fig. 2) (46,89-91). For better instrumentation efficacy, a higher proportion of MCW is expected (46,89-91).

\section{Axial Root Strain}

\subsection{Definition of Strain}

Strain is the resultant deformation due to an applied stress (97). It is calculated as the change in length $(\Delta \mathrm{L})$ relative to the original length $\left(\mathrm{L}_{0}\right)$ and expressed mathematically using the following formula: Strain $=\varepsilon=\Delta \mathrm{L} / \mathrm{L}_{0}$. As strain is a relative change, the measurement has no units but is reported by convention as "meter/meter" or "m/m". Strain can be compressive if the material becomes smaller than the original length (expressed as a negative value), or tensile if the material increases in length (97).

\subsection{Application of Strain Measurements in Teeth}

Measurement of strain produced on the crown and root surfaces of teeth can elucidate biomechanical impacts of dental treatments (62-66). Previously reported methods to measure deformation in teeth include strain gauges, linear variable differential transformers and direct current differential transformers (62-66). Use of strain gauges is relatively simple and involves attaching strain gauges with cyanoacrylate to the surface of the material under investigation (63$65,98,99)$. Strain gauges are thin metallic wires or foil that conduct a current and are embedded in a plastic sheath. The gauges are connected to a data acquisition module in an electric circuit with a half or full wheatstone bridge (99). As the material under investigation deforms upon applied stress, the gauges also deform causing a change in their electric resistance and 
consequently in the resting voltage of the circuit. This altered voltage is converted to an output measurement for strain and captured with a computer (Fig. 3).

Axial strain measurement on the crown and root surface of teeth has been used previously to investigate effects of coronal tooth structure loss due to operative dental procedures (63-65). Increasing removal of tooth structure, especially removal of a marginal ridge such as for a Class II restoration, increases surface strain and cuspal deflection $(64,100)$.

Strain due to polymerization shrinkage of bonded resin composite restorations has also been studied $(101,102)$. During polymerization, the shrinkage of the curing composite resin exerts tensile strains on the bonded tooth structure, possibly leading to failure at the restorative-tooth interface $(101,102)$. The bonded composite resin restorations decrease surface strains under functional loading and partially or totally restore tooth stiffness lost due to the operative procedure $(101,102)$.

\section{Fracture Strength of Root-Filled Teeth}

\subsection{Structural Properties of Root-Filled Teeth}

Root-filled teeth are complex structures with mechanical properties derived mostly from dentin and, to a lesser extent, enamel $(103,104)$. Young's elastic modulus of compression is derived from the elastic region of the stress-strain curve and is a measurement of "stiffness", which for dentin is approximately $18.6 \mathrm{GPa}$ and for enamel is $84.1 \mathrm{GPa}(76,103,105)$. Early reports asserted endodontically treated teeth were more brittle due to loss of moisture content (106). While the moisture content of collagen-rich dentin significantly impacts the mechanical properties (107), studies have concluded the moisture content of vital and root-filled teeth were 
similar at approximately $12 \%$ (108). Thus, root-filled teeth per se do not differ significantly from vital teeth in their mechanical properties $(103,108-110)$. However, they are more likely to have sustained tooth structure loss during removal of caries and during root canal treatment $(12,45)$. Furthermore, endodontic procedures such as instrumentation and root-filling may generate dentin defects or cracks $(111,112)$, which may progress over time $(103,113)$. Studies have concurred that maximum preservation of natural tooth structure favors restorability and maintains mechanical properties of teeth $(9,13,45,46)$.

\subsection{Testing Fracture Strength of Teeth}

\subsubsection{Cyclic Fatigue}

Masticatory function has been reported to exhibit average forces ranging from 9 to $45 \mathrm{~N}$ over approximately 250,000 cycles per year $(112,114,115)$. Crack propagation is considered a fatiguemediated process that progresses with time $(103,104,113)$. Consequently, cyclic loading is used to simulate clinical function of restored teeth $(113,115,116)$. Cyclic loading has been used to investigate the number of cycles required to induce failure (117) or as a fatiguing mechanism to simulate years of clinical function $(113,115)$. Additionally, "chewing machines" have also been used that more accurately replicate the complex masticatory movements in more than a single axial plane (115).

\subsubsection{Load-at-Failure}

Fracture strength, also referred to as fracture resistance, is an assessment of stress causing a fracture of the investigated material $(97,103,104)$. Stress is defined as the force per crosssectional area over which the force is applied according to the following equation: $\sigma=\mathrm{F} / \mathrm{A}$, 
where $\sigma=$ stress (Pascals); $\mathrm{F}=$ force $\left(\right.$ Newtons); $\mathrm{A}=$ area $\left(\mathrm{m}^{2}\right)$. Fracture strength can be assessed with the Instron Universal Testing Machine (Instron, Canton, MA) as it is able to deliver precisely controlled forces over a selected cross-section. The stress generated for a given force is inversely proportional to the cross-sectional area over which the force is applied and can thus influence the results when measuring the force at which fracture occurs (74). Studies commonly use a spherical cross-head with a diameter of approximately $5 \mathrm{~mm}$ when assessing fracture strength of teeth $(73,85,118)$, while use of different sizes have also been reported (74).

Although complete fracture of a tooth in the Instron Universal Testing Machine may occur at extremely high stresses, cracks form at lower stresses as the force is slowly increased (107). These cracks cause sudden decreases in the applied stress and thus the initial "failure" of a given tooth is then defined when the applied force experiences a sudden drop exceeding a chosen percentage (Fig. 5) (46).

\section{Objectives and Hypotheses}

In a previous in-vitro study by our research group (46), mandibular premolars and molars with CEC exhibited higher fracture strength under continuous load than similar teeth with TEC; however, compromised instrumentation efficacy was suggested in the distal canals of mandibular molars with CEC. No such impairment was observed in mandibular premolars and in maxillary incisors and no improvement in fracture strength was observed in the latter (46), suggesting that the impact of CEC varied in different tooth types due to their specific morphologies.

Our previous results regarding the impacts of CEC in maxillary incisors and mandibular premolars and molars (46), might not be extrapolated to maxillary molars where the morphology 
is distinctly different. Also, data on fracture resistance of maxillary molars appear to be sparse (119) unlike data on mandibular molars $(46,73,74,85,86,118)$. Therefore, the aim of this in-vitro study was to assess the impacts of CEC in maxillary molars with respect to:

- Instrumentation efficacy using proportion of modified canal wall assessed with microCT.

- Axial strain responses measured pre- and post-operatively with strain gauges.

- Fracture strength using load-at-failure under continuous compressive force applied in the Instron Universal Testing machine after 1 million cycles of fatiguing.

We tested the following null hypotheses:

1. The proportion of modified canal wall, as assessed with micro-CT, does not differ significantly between CEC and TEC.

2. The change in axial strain, as assessed with strain gauges at the mesio-buccal and palatal root surfaces, does not differ significantly between CEC and TEC.

3. The fracture strength, as assessed in the Instron Universal Testing machine, does not differ significantly between CEC, TEC and intact controls. 


\section{Article}

\section{Submitted for Publication}

Impacts of Contracted Endodontic Cavities on Instrumentation Efficacy and

Biomechanical Responses in Maxillary Molars.

Brent Moore, DMD ${ }^{\mathrm{a}}$, Kostas Verdelis, DDS, $\mathrm{PhD}^{\mathrm{b}}$, Anil Kishen, MDS, $\mathrm{PhD}^{\mathrm{c}}$, Thuan Dao, DMD, MSc, Dip. Prostho., PhD, FRCD(C) , Shimon Friedman, DMD ${ }^{\mathrm{a}}$

${ }^{a}$ M.Sc. Endodontics Program, University of Toronto, 124 Edward Street, Toronto ON M5G

1G6, Canada

${ }^{b}$ Division of Endodontics, School of Dental Medicine, University of Pittsburgh, 3501 Terrace

Street, Pittsburgh, PA 15213

${ }^{c}$ Discipline of Endodontics \& Dental Research Institute, Faculty of Dentistry, University of Toronto, ON M5G 1G6, Canada

${ }^{\mathrm{d}}$ Discipline of Prosthodontics, University of Toronto, 124 Edward Street, Toronto ON M5G

1G6, Canada

\section{Corresponding Author:}

Shimon Friedman DMD

Professor, M.Sc. Endodontics Program, Faculty of Dentistry, University of Toronto

Email: shimon.friedman@dentistry.utoronto.ca

Contact: 1-416-979-7900 (x4403)

\section{Acknowledgements:}

The authors thank Dr. Rong Chong for processing the micro-CT data.

Supported in part by the American Association of Endodontists Foundation and the Canadian Academy of Endodontics Endowment Fund.

The authors deny any conflict of interest related to this study. 


\section{Highlights:}

- This study evaluated contracted (CEC) and traditional endodontic cavities (TEC) with respect to instrumentation efficacy, axial strain response at the mesio-buccal and palatal root surfaces and load-at-failure under static compressive loading applied after cyclic loading.

- Instrumentation efficacy was not significantly impacted by endodontic cavity design.

- Axial root strain varied without consistent patterns for CEC or TEC under cyclic loading.

- Load-at-failure for CEC did not differ significantly from TEC, and was lower for both groups compared to intact molars controls.

\section{Clinical Relevance:}

Fracture after endodontic treatment is an ongoing concern. Modern dentistry has seen a trend towards minimally invasive treatments. In endodontics, removal of tooth structure increases the susceptibility of teeth to fracture which gave rise to contracted cavities. 


\begin{abstract}
Introduction: Recently, we reported that in mandibular molars, contracted endodontic cavities (CEC) improved fracture strength compared to traditional endodontic cavities (TEC), but compromised instrumentation efficacy in distal canals. This study assessed impacts of CEC on instrumentation efficacy and axial strain responses in maxillary molars.
\end{abstract}

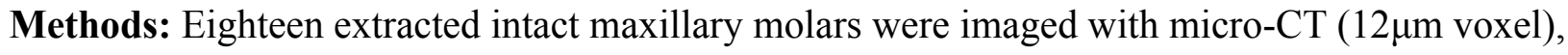
assigned to CEC or TEC groups ( $\mathrm{n}=9$ /group) and accessed accordingly. Canals were instrumented (V-Taper2H, SSWhite Dental) with 2.5\% NaOCl irrigation, re-imaged and proportion of modified canal wall (MCW) determined. Cavities were restored with bonded composite resin (TPH-Spectra-LV, Dentsply International). Another 28 similar molars ( $n=14$ /group) with linear strain gauges (Showa Measuring Instruments) attached to buccal and palatal roots were subjected to load cycles $(50-150 \mathrm{~N})$ in the Instron Universal Testing machine and axial microstrain recorded before access and after restoration. These 28 molars and additional 11 intact molars (control) were cyclically fatigued (1 million cycles, $5-50 \mathrm{~N}, 15 \mathrm{~Hz})$ and subsequently loaded to failure. Data were analyzed by Wilcoxon rank sum and KruskalWallis tests $(\alpha=0.05)$.

Results: Mean proportion of MCW did not differ significantly between CEC (49.7 $\pm 12.0 \%)$ and TEC (44.7 $\pm 9.0 \%)$. Changes in axial microstrain responses to load varied in both groups. Mean load-at-failure for CEC $(1703 \pm 558 \mathrm{~N})$ did not differ significantly from TEC $(1384 \pm 377 \mathrm{~N})$ and was significantly lower $(\mathrm{p}<0.005)$ for both groups compared to intact molars $(2457 \pm 941 \mathrm{~N})$. 
Conclusions: In maxillary molars tested in-vitro, CEC did not appear to impact instrumentation efficacy and biomechanical responses compared to TEC. Supported by AAE Foundation and CAE Endowment Fund.

Key Words: endodontic cavity, fracture strength, instrumentation efficacy, minimally invasive, root strain 


\section{Introduction}

Endodontic treatment aims to retain teeth in health and function for the long term (1) but teeth may fracture, necessitating extraction (2-4). A fracture risk factor is loss of dentin, including that associated with drilling of endodontic cavities (4). Traditional endodontic cavities (TEC) emphasize straight-line pathways into canals to enhance instrumentation efficacy and prevent procedural errors $(5,6)$. Associated removal of pericervical dentin $(7,8)$ can impact biomechanical responses of teeth (9-14) including strain occurring at the crown and root surfaces (11-13). Thus, increased cuspal flexure associated with TEC $(9,12-14)$ may lead to increased crown-root surface strain and susceptibility of treated teeth to fracture under functional loads $(4,9)$, even if bonded composite resin restorations may moderate these biomechanical effects in the short term $(12,15-18)$.

Contracted endodontic cavities (CEC), inspired by concepts of minimally-invasive dentistry (19), emphasize tooth structure preservation including pericervical dentin $(7,8)$. We previously reported (20) that CEC, compared with TEC, improved fracture strength under continuous load in mandibular premolars and molars but not in maxillary incisors, while compromising instrumentation efficacy in distal canals of mandibular molars but not in premolars and incisors. While these results suggested that impacts of CEC varied in different tooth types, they might not be extrapolated to maxillary molars where the morphology is distinctly different. Also, unlike available data on fracture strength of intact mandibular molars (21), respective data on maxillary molars is lacking. Therefore, this study assessed impacts of CEC on canal instrumentation efficacy and biomechanical responses in maxillary molars. We tested the null hypotheses that CEC would not impact on either of instrumentation efficacy, axial root strain and fracture strength after cyclic fatigue. 


\section{Materials and Methods}

After research protocol approval by the University of Toronto Research Ethics Board, 59 extracted human non-carious, mature, intact, maxillary molars were stored in $0.1 \%$ thymol solution at room temperature until used. Absence of pre-existing cracks was verified under the operating microscope. Crown dimensions, length and canal curvature of teeth, determined by two perpendicular radiographic exposures, were considered for matching teeth allocated into groups.

\section{Sample and Groups}

Sample size was estimated based on studies comparing fracture strength for TEC and CEC (20) and proportion of untouched canal wall (20,22-24), both with 10 teeth/group. Accordingly, for analysis with $\alpha=0.05$ and $80 \%$ power, at least 10 teeth were allocated for each of the following groups: CEC (experimental), TEC (control) and Intact (negative control for fracture testing) for different aspects of the study.

\section{Instrumentation Efficacy}

Subset of 20 teeth assigned to CEC and TEC were imaged with micro-CT (SkyScan 1172, Brüker MicroCT, Kontich, Belgium) at $12 \mu \mathrm{m}$ voxel size, $70 \mathrm{KVp}$ beam energy, 10 frames/view and 400ms exposure, and the canals captured (pre-treatment volumes). Mineral density was calibrated with mineral-analogue rods and ReCon software (Brüker MicroCT) used for 3D reconstruction.

Eighteen teeth (1 tooth/group was lost during processing) were accessed under the operating microscope. In CEC group ( $\mathrm{n}=9$ ), endodontic cavities were drilled with high-speed Endoguide 
burs (EG1A; SSWhite Dental, Lakewood, NJ). Cavities were accessed at the central fossa and extended only as necessary to access canal orifices while preserving pericervical dentin and part of the chamber roof or "soffit" $(7,8)$ (Fig. 1A). In TEC group (n=9), endodontic cavities were drilled with tapered high-speed diamond burs (F392-016; Axis Dental, Coppell, TX) following conventional guidelines $(5,6)$. Outline and pericervical dentin were modified as needed until all orifices could be visualized in the same field of view.

Canals were negotiated with size 10 K-type files (Flexofile; Dentsply-Maillefer, Ballaigues, Switzerland) to the major apical foramen and the working length (WL) established $0.5 \mathrm{~mm}$ shorter. After initial preparation with PathFile instruments (Dentsply-Maillefer), canals were instrumented with V-Taper2H rotary instruments (SSWhite Dental) to size 20/v06 and 30/v06 in buccal and palatal roots, respectively. These heat-treated instruments were pre-curved to facilitate placement into canals. Intermittent irrigation with $5 \mathrm{~mL}$ of $2.5 \%$ sodium hypochlorite was applied with ProRinse side-vented 30-G needles (Dentsply International, York, PA).

Instrumented canals were captured with micro-CT (post-treatment volumes) as described above. Reconstructed 3D volume data were converted from BMP to DICOM format and processed with Scanco 3D morphometry analysis software (Scanco Medical, Brüttisellen, Switzerland). Coronal canal boundaries were set at orifice levels. Customized script for algorithm-based registration $(20,22,24)$ was used to process pre- and post-treatment volumes with precision of $1 \pm 1$ voxel. Accordingly, dentin removal depth $\geq 24 \mu \mathrm{m}$ was determined as modified canal wall (MCW) surface.

\section{Biomechanical Responses}


Another subset of 28 teeth was used to record apico-coronal axial strain under simulated physiologic occlusal stresses $(10,11)$. Teeth were mounted up to $3 \mathrm{~mm}$ apical to the cementoenamel junction in customized cylinders fabricated with self-curing resin (SR Ivolen; Ivoclar Vivadent, Schaan, Lichtenstein), with $0.2 \mathrm{~mm}$-thick lining of polyvinyl siloxane (Aquasil Ultra Monophase Regular Set, Dentsply International) simulating the periodontal ligament. Foil strain gauges (N11-FA-2-120-11, Showa Measuring Instruments, Tokyo, Japan) were glued with rapidsetting cyanoacrylate adhesive (Instant Adhesive Aron Extra 4000, Toagosei, Tokyo, Japan) on the mesio-buccal and palatal cervical root surfaces (10-14) and sealed with polyurethane varnish (PU140, Hottinger Baldwin Messtechnik, Darmstadt, Germany).

Teeth were mounted in the Instron Universal Testing machine (IUT) (Instron, Canton, MA). Axial forces, directed at $30^{\circ}$ angle from the tooth's long axis, were cycled between $50 \mathrm{~N}$ and $150 \mathrm{~N}$ and the voltage-change outputs from the strain gauges, connected by a half-wheatstone bridge, converted to strain measurements by a data acquisition module (DQ 430 EspressoDAQ, HBM Canada, Pickering, ON). Microstrain values were recorded using DAQ software (Catman Easy, EspressoDAQ version 1.02, HBM Canada) at each of the mesio-buccal and palatal surfaces.

Canals of the 28 teeth were accessed as per CEC and TEC group designation ( $\mathrm{n}=14$ /group) and instrumented as described above. Subsequently, endodontic cavities were etched with $38 \%$ phosphoric acid gel (Etch-Rite ${ }^{\mathrm{TM}}$, Watertown, MA), rinsed with water, air-dried, coated with OptiBond $^{\mathrm{TM}}$ Solo Plus (Kerr Corp., Orange, CA), air-dried and restored with TPH Spectra Universal Composite Restorative LV (Dentsply International) applied in $<2 \mathrm{~mm}$ increments, each cured for $20 \mathrm{sec}$. Teeth were then stored in $0.1 \%$ thymol solution at room temperature for 2 weeks and microstrain measurements repeated. 
Subsequently, the 28 teeth assigned to CEC and TEC and remaining subset of 11 teeth were submerged in a water bath at room temperature and subjected to 1 million loading cycles in the IUT between $5 \mathrm{~N}$ and $50 \mathrm{~N}$ at $15 \mathrm{~Hz}$, to simulate approximately four years of chewing function (25) using forces within the physiological range (26). After this fatigue phase, continuous compressive force was applied with a $5 \mathrm{~mm}$ spherical crosshead at $1 \mathrm{~mm} / \mathrm{min}$ until failure occurred, defined as $25 \%$ drop in applied force, and the load-at-failure recorded $(\mathrm{N})$.

\section{Analysis}

MCW was expressed as proportion of total canal wall area for the coronal and apical halves of each root. Corresponding mean MCW values for CEC and TEC groups were analyzed with Wilcoxon Rank Sum test. Average pre- and post-treatment microstrain values were calculated separately for mesio-buccal and palatal surfaces of each tooth. Corresponding values for CEC and TEC groups were analyzed with Wilcoxon Signed Rank Sum test. In addition, relative stiffness (pre-treatment value divided by post-treatment value) was determined as previously reported and evaluated qualitatively (11). Mean load-at-failure values were calculated for CEC, TEC and Intact control groups and analyzed with Kruskal-Wallis and post hoc Dunn's test. All tests were 2-tailed and significance set at 5\% level.

\section{Results}

\section{Instrumentation Efficacy}

No instruments fractured during canal preparation. Fig. 1B shows registered pre- and posttreatment reconstructed micro-CT images of a molar with CEC. Mean proportion of MCW (Table 1) was highest in the coronal half of disto-buccal canals in CEC group (59.7 \pm 16.8$)$ and 
lowest in the apical half of palatal canals in TEC group (34.6 \pm 15.4$)$. It did not differ significantly $(\mathrm{P}>0.15)$ between CEC and TEC groups in any of the roots and canal levels.

\section{Biomechanical Responses}

Fig. 2 depicts axial microstrain measurements obtained from a molar with CEC. Pre- and posttreatment microstrain values did not differ significantly between mesio-buccal and palatal surfaces of teeth and between CEC and TEC groups. Median relative stiffness values were higher at palatal surfaces (CEC 0.74; TEC 0.94) than at mesio-buccal surfaces (CEC 0.33; TEC $0.37)$.

Mean load-at-failure values (Fig. 3) did not differ significantly between CEC $(1703 \pm 558 \mathrm{~N}$; range, $1205-3021 \mathrm{~N})$ and TEC $(1384 \pm 377 \mathrm{~N}$; range, 966-2381N) groups, but were significantly lower $(\mathrm{P}<0.05)$ for both groups compared to Intact controls $(2457 \pm 941 \mathrm{~N}$; range, $1252-3806 \mathrm{~N})$. Fractures were mesial-distal and buccal-palatal with varying levels of apical extension but no apparent pattern observed in any group.

\section{Discussion}

To apprise the debate on the CEC concept, we previously assessed impacts of CEC designs in three tooth types (20). Improved fracture strength - a potential benefit - was observed in mandibular premolars and molars but not in maxillary incisors; compromised canal instrumentation efficacy - a potential risk - was observed only in distal canals of mandibular molars (20). The varied impacts of CEC in the different tooth types (20) warranted the present investigation into specific impacts of CEC in these teeth. 
Mature, intact maxillary molars were used to avoid effects of varying degrees of tooth structure loss. While matched for external dimensions when allocated to CEC and TEC groups, some teeth in both groups had fairly large pulp chambers and short roots, limiting the applicability of the results to maxillary molars with similar characteristics. The canals were instrumented with VTaper2H instruments size 20/v06 and 30/v06. Due to the regressive taper design, their D12 diameters $(0.64 \mathrm{~mm}$ and $0.74 \mathrm{~mm}$, respectively) are smaller than respective diameters of continuously tapered $20 / 04$ and $20 / 06$ instruments $(0.68 \mathrm{~mm}$ and $0.92 \mathrm{~mm}$, respectively). With smaller D12 dimensions, less pericervical dentin removal was expected than would occur with other instruments. In addition, increased flexibility and cyclic fatigue resistance of the heattreated instruments, compared to similar non-treated instruments (27), were deemed desirable considering the constrained pathways to canals. Indeed, no instrument fracture or ledge formation occurred in any of the teeth. Instrumentation efficacy was assessed with higher resolution micro-CT imaging than in previous studies $(20,22-24)$, providing a threshold of $1 \pm 1$ voxel, or $24 \mu \mathrm{m}$ to detect canal-wall modification.

Of several methods applied for axial strain or cuspal deflection analysis (9-11), strain gauges were chosen to detect slight changes in microstrain (10) and to directly compare pre- and posttreatment axial microstrain within the same tooth. The fine metal-foil strain gauge conducts current with given electrical resistance and static voltage. The gauge deforms when underlying tooth structure deflects under loading, and the resulting change in electrical resistance is detected and converted to a measurement. Importantly, although forces in the physiologic range were applied (26), axial microstrain assessment may not reflect complete root strain patterns for the complex chewing process (26). 
Endodontic cavities were restored with bonded composite resin to simulate clinical procedures while facilitating loading. Such restorations may restore fracture strength of teeth up to $72 \%$ of that of intact teeth (17). Teeth were fatigued with cyclic loading since fractures in root-filled teeth are considered to be fatigue failures, arising from micro-defects within dentin and at restoration-tooth interfaces (28). While standard deviations of load-at-failure values were larger than what we observed in mandibular molars (20), they were consistent with other fracture studies of molar teeth $(18,21)$.

No significant difference in instrumentation efficacy was detected in the maxillary molars with CEC and TEC. It was poor overall; instrumentation modified $49 \%$ to $59 \%$ of buccal canal walls and about $38 \%$ of palatal canal walls, corroborating the limited efficacy of engine-driven instruments previously shown in all tooth types $(20,22,23)$. While in this study we instrumented rather wide canals with modestly-sized instruments, instrumentation efficacy was comparable to what we reported in mandibular molars (20) with CEC ( $43 \%$ to $52 \%)$ and TEC ( $52 \%$ to $63 \%$ ), and only slightly below the $55 \%$ to $67 \%$ reported elsewhere in maxillary molars $(22,23)$. Instruments' contact with canal walls is needed to mechanically debride pulp tissue and disrupt bacterial biofilm (29). The lack of detected compromise in instrumentation efficacy in maxillary molars with CEC suggested no apparent risk in this regard.

Axial microstrain varied without a discernible pattern for CEC and TEC groups. Intra-canal dentin removal increases root deformation (14) and tooth structure loss increases strain in teeth $(12,13)$. The minimal change in microstrain at palatal root surfaces and greater changes at the mesio-buccal root surfaces, in maxillary molars from both groups, suggested that the mesiobuccal cusp was more prone to deformation after access and canal instrumentation than the relatively robust palatal cusp. The relative stiffness might also be affected by the polymerization 
shrinkage of the bonded composite resin restorations (30), whereby resulting contractile forces produced tensile strain (30) leading to increased tooth stiffness (31).

No significant difference in fracture strength was detected between the restored maxillary molars with CEC and TEC and in both it was consistently lower than that of intact molars. The nonsignificant $23 \%$ increase in fracture strength for CEC compared to TEC sharply contrasted with the $247 \%$ increase we reported for unrestored mandibular molars with CEC (20) and it did not reach the fracture strength level of intact maxillary molars as it did in mandibular molars (20). Thus, CEC in maxillary molars did not appear to positively impact fracture strength suggesting equivocal benefit in this regard. The compromised fracture strength even with CEC supported use of cuspal or full coverage definitive restorations to limit tooth structure deformation and possible fracture, as recommended for posterior endodontically treated teeth $(2,4,11,32,33)$.

Fracture strength of intact maxillary molars was reported previously at 4960 $\pm 1147 \mathrm{~N}$ (34), which is considerably greater than the mean load-at-failure just below $2,500 \mathrm{~N}$ after cyclic fatiguing herein. Interestingly, the current load-at-failure of intact maxillary molars was $21 \%$ higher than the $2029 \mathrm{~N}$ we reported for non-fatigued intact mandibular molars (20). Though use of cyclic fatiguing herein precluded direct comparison, the results suggested greater robustness of maxillary molars that might moderate the risk of fracture after endodontic treatment. Indeed, Zadik et al. (33) reported a much lower incidence of fracture among endodontically treated maxillary molars compared to mandibular molars.

Minimally-invasive dentistry interventions (19), highlighting preservation of natural tissues, require successful intersection of (i) specific benefits outweighing potential risks, (ii) proceduredriven technologies and (iii) skills adaptation by clinicians $(7,8)$. While minimally-invasive interventions have been embraced in some areas of dentistry (19), the CEC concept in 
endodontics has largely been opposed because it poses challenges not encountered with TEC (5). Technologies - operating microscopes and improved nickel-titanium instruments - are available that enable treatment with less convenience form $(7,8)$. Whether clinicians should strive to adapt skills for routine use of CEC should, therefore, hinge on clinically proven benefits (lower fracture rates) and dismissed risks (no compromised healing). Until such clinical evidence becomes available, in-vitro research can suggest benefits and risks. This in-vitro study neither supported apparent biomechanical benefits nor an instrumentation efficacy risk associated with CEC in maxillary molars, in line with our observations in maxillary incisors but not in mandibular premolars and molars (20). Considering that maxillary molars present with particularly challenging root canal systems in mesio-buccal roots, where secondary canals are difficult to locate and negotiate (35), the application of CEC in these teeth merits careful consideration. In conclusion, given the limitations of in-vitro testing, CEC in maxillary molars did not appear to impact instrumentation efficacy and biomechanical responses compared to TEC. 


\section{References}

1. de Chevigny C, Dao TT, Basrani BR, Marquis V, Farzaneh M, Abitbol S, et al. Treatment outcome in endodontics: the Toronto study-phase 4: initial treatment. J Endod 2008;34:258-63.

2. Borén DL, Jonasson P, Kvist T. Long-term survival of endodontically treated teeth at a public dental specialist clinic. J Endod 2015;41:176-81.

3. Fransson H, Dawson VS, Frisk F, Bjørndal L, Kvist T. Survival of root-filled teeth in the swedish adult population. J Endod 2016;42:216-20.

4. Tang W, Wu Y, Smales RJ. Identifying and reducing risks for potential fractures in endodontically treated teeth. J Endod 2010;36:609-17.

5. Goerig AC, Michelich RJ, Schultz HH. Instrumentation of root canals in molar using the step-down technique. J Endod 1982;8:550-4.

6. Schroeder KP, Walton RE, Rivera EM. Straight line access and coronal flaring: effect on canal length. J Endod 2002;28:474-6.

7. Clark D, Khademi J. Modern molar endodontic access and directed dentin conservation. Dent Clin North Am 2010;54:249-73.

8. Bóveda C, Kishen A. Contracted endodontic cavities: the foundation for less invasive alternatives in the management of apical periodontitis. Endod Top 2015;33:169-86.

9. Panitvisai P, Messer H. Cuspal deflection in molars in relation to endodontic and restorative procedures. J Endod 1995;21:57-61.

10. Jantarat J, Panitvisai P, Palamara JE, Messer HH. Comparison of methods for measuring cuspal deformation in teeth. J Dent 2001;29:75-82.

11. Reeh ES, Messer HH, Douglas WH. Reduction in tooth stiffness as a result of endodontic and restorative procedures. J Endod 1989;15:512-6.

12. Soares PV, Santos-Filho PCF, Gomide HA, Araujo CA, Martins LRM, Soares CJ. Influence of restorative technique on the biomechanical behavior of endodontically treated maxillary premolars. Part II: Strain measurement and stress distribution. J Prosthet Dent 2008;99:114-22.

13. Pereira J, McDonald A, Petrie A, Knowles J. Effect of cavity design on tooth surface strain. J Prosthet Dent 2013;110:369-75.

14. Lang H, Korkmaz Y, Schneider K, Raab WH-M. Impact of endodontic treatments on the rigidity of the root. J Dent Res 2006;85:364-8.

15. Hofmann N, Just N, Hugo B, Haller B. The effect of glass ionomer cement or composite resin bases on restoration of cuspal stiffness of endodontically treated premolars in vitro. Clin Oral Investig 1998;2:77-83.

16. Moezizadeh M, Mokhtari N. Fracture resistance of endodontically treated premolars with fibre-reinforced composite restorations. J Conserv Dent 2011;14:277-81.

17. Hamouda IM, Shehata SH. Fracture resistance of posterior teeth restored with modern restorative materials. J Biomed Res 2011;25:418-24. 
18. Plotino G, Buono L, Grande NM, Lamorgese V, Somma F. Fracture resistance of endodontically treated molars restored with extensive composite resin restorations. $\mathrm{J}$ Prosthet Dent 2008;99:225-32.

19. Murdoch-Kinch CA, McLean ME. Minimally invasive dentistry. J Am Dent Assoc 2003;134:87-95.

20. Krishan R, Paqué F, Ossareh A, Kishen A, Dao T, Friedman S. Impacts of conservative endodontic cavity on root canal instrumentation efficacy and resistance to fracture assessed in incisors, premolars, and molars. J Endod 2014;40:1160-6.

21. Watts D, El Mowafy O, Grant A. Fracture resistance of lower molars with class 1 composite and amalgam restorations. Dent Mater 1987;3:261-4.

22. Peters O, Laib A, Göhring T, Barbakow F. Changes in root canal geometry after preparation assessed by high-resolution computed tomography. J Endod 2001;27:1-6.

23. Peters O, Peters C, Schönenberger K, Barbakow F, Scho K. ProTaper rotary root canal preparation: effects of canal anatomy on final shape analysed by micro CT. Int Endod J 2003;36:86-92.

24. Paqué F, Ganahl D, Peters O. Effects of root canal preparation on apical geometry assessed by micro-computed tomography. J Endod 2009;35:1056-9.

25. DeLong R, Sakaguchi RL, Douglas WH, Pintado MR. The wear of dental amalgam in an artificial mouth: a clinical correlation. Dent Mater 1985;1:238-42.

26. De Boever JA, McCall Jr WD, Holden S, Ash Jr MM. Functional occlusal forces: An investigation by telemetry. J Prosthet Dent 1978;40:326-33.

27. Shen Y, Zhou H, Zheng Y, Campbell L, Peng B, Haapasalo M. Metallurgical characterization of controlled memory wire nickel-titanium rotary instruments. J Endod 2011;37:1566-71.

28. Kishen A. Mechanisms and risk factors for fracture predilection in endodontically treated teeth. Endod Top 2006;17:57-83.

29. Haapasalo M, Endal U, Zandi H, Coil JM. Eradication of endodontic infection by instrumentation and irrigation solutions. Endod Top 2005;10:77-102.

30. Meredith N, Setchell DJ. In vitro measurement of cuspal strain and displacement in composite restored teeth. J Dent 1997;25:331-7.

31. Morin DL, Cross M, Voller VR, Douglas WH, DeLong R. Biophysical stress analysis of restored teeth: modelling and analysis. Dent Mater 1988;4:77-84.

32. Linn J, Messer HH. Effect of restorative procedures on the strength of endodontically treated molars. J Endod 2010;20:479-85.

33. Zadik Y, Sandler V, Bechor R, Salehrabi R. Analysis of factors related to extraction of endodontically treated teeth. Oral Surg Oral Med Oral Pathol Oral Radiol Endod 2008;106:31-5.

34. Rodrigues FB, Paranhos MPG, Spohr AM, Oshima HMS, Carlini B, Burnett LH. Fracture resistance of root filled molar teeth restored with glass fibre bundles. Int Endod $\mathrm{J}$ 2010;43:356-62. 
35. Görduysus M, Görduysus M, Friedman S. Operating microscope improves negotiation of second mesiobuccal canals in maxillary molars. J Endod 2001;27:683-6. 


\section{Legends to Figures}

Fig. 1. Contracted endodontic cavity (CEC) in a maxillary molar. (A) Occlusal view; for comparison, a traditional cavity (TEC) is outlined with a dotted line. (B) Distal view of registered 3D reconstructed micro-CT images showing the root canals pre-treatment (red) and post-treatment (yellow).

Fig. 2. Axial microstrain measured at mesio-buccal and palatal cervical root surfaces of a maxillary molar under simulated physiologic loads $(50-150 \mathrm{~N})$ in the Instron Universal Testing machine. Measurements were obtained before access (pre-op) and after contracted (CEC) access, canal instrumentation and bonded composite resin restoration (post-op). While the pre- and postop measurements at the palatal surface were similar, the measurements at the mesio-buccal surface changed from compressive microstrain pre-op, to tensile microstrain post-op.

Fig. 3. Mean load-at-failure in maxillary molars, intact (control) or with restored contracted (CEC) or traditional (TEC) access, under compressive load preceded by 1 million cycles of fatiguing loads in the Instron Universal Testing machine. 
Fig. 1.
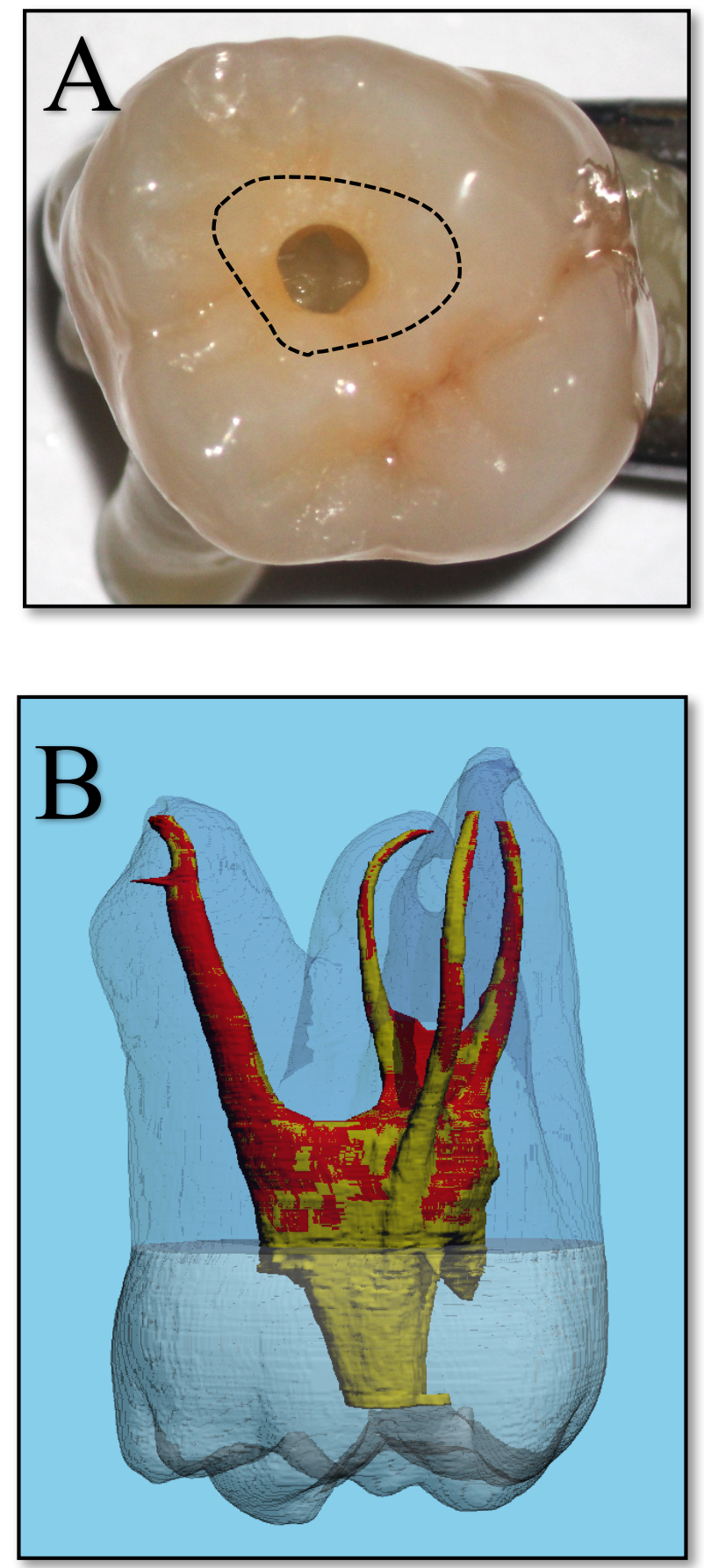
Fig. 2.

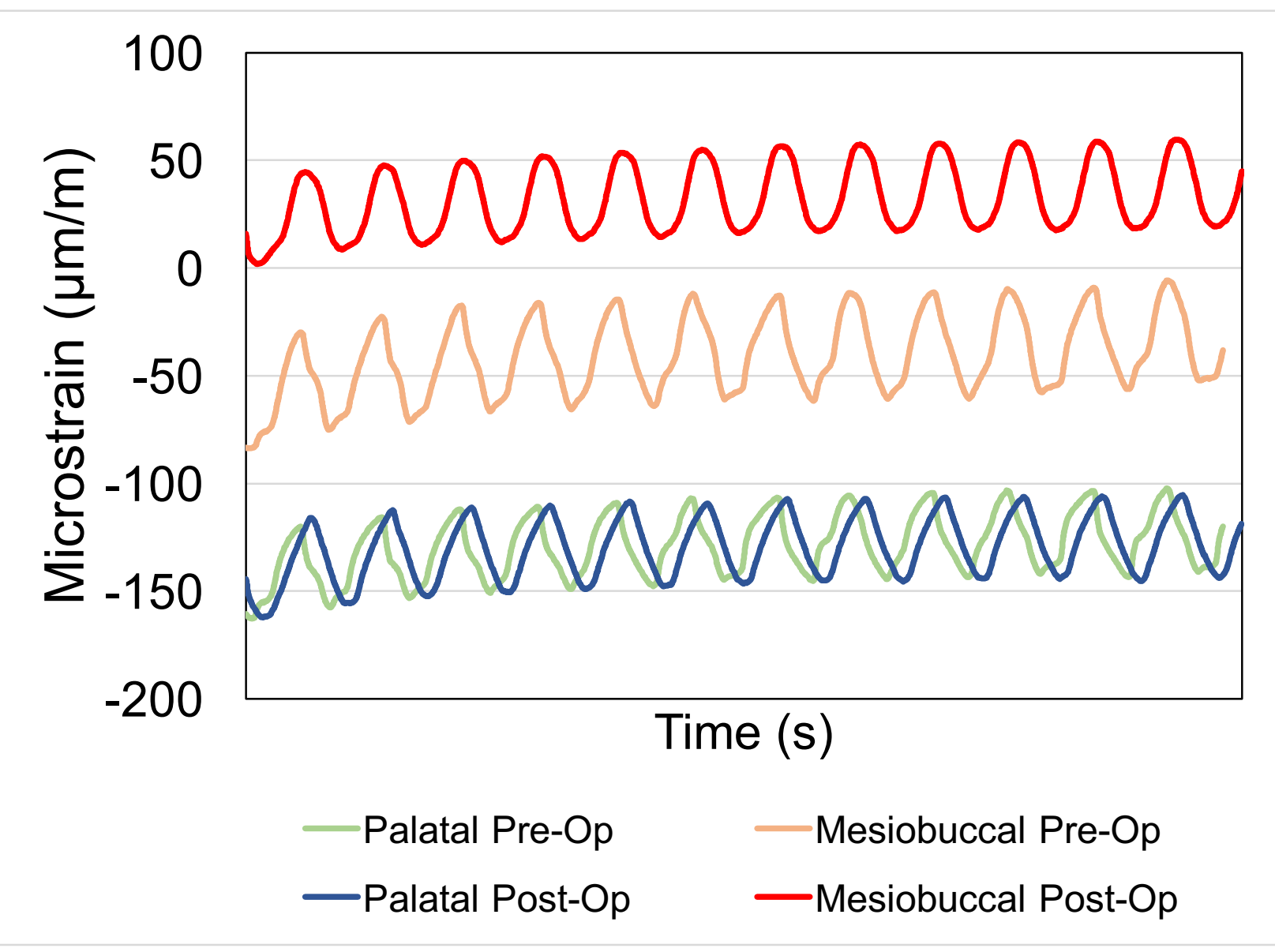


Fig. 3.

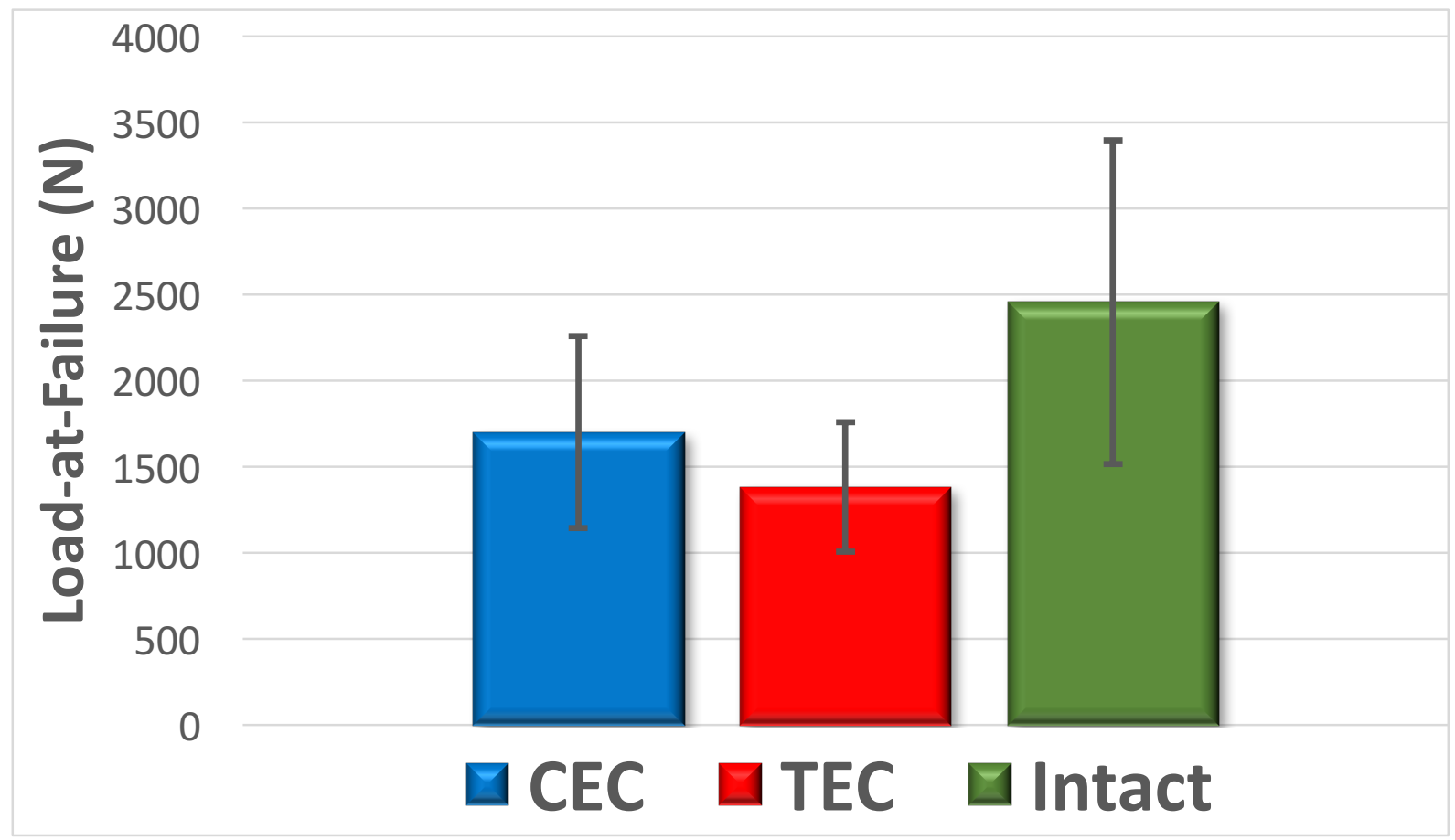


Table 1. Modified Canal Wall (MCW) after instrumentation in maxillary molars performed through contracted (CEC) or traditional (TEC) cavity, assessed by micro-CT. MCW is expressed as proportion of the total canal wall area; mean and standard deviation values presented by coronal and apical halves of the three roots.

\begin{tabular}{|l|l|c|c|}
\hline \multirow{2}{*}{$\begin{array}{c}\text { Root } \\
(\mathrm{n}=9)\end{array}$} & \multicolumn{1}{c|}{$\begin{array}{c}\text { Assessed canal } \\
\text { level }\end{array}$} & \multicolumn{2}{|c|}{$\begin{array}{c}\text { Modified Canal Wall } \\
\text { (\% of total canal wall surface })\end{array}$} \\
\cline { 3 - 4 } & & CEC & TEC \\
\hline \multirow{3}{*}{ Mesio-buccal } & Coronal half & $57.1 \pm 18.2$ & $54.3 \pm 17.0$ \\
& Apical half & $49.2 \pm 10.1$ & $45.1 \pm 18.6$ \\
& Total canal & $53.1 \pm 11.6$ & $49.7 \pm 16.5$ \\
\hline \multirow{3}{*}{ Disto-buccal } & Coronal half & $59.7 \pm 16.8$ & $51.6 \pm 12.2$ \\
& Apical half & $58.3 \pm 14.4$ & $46.7 \pm 9.8$ \\
\hline \multirow{3}{*}{ Palatal } & Total canal & $59.0 \pm 14.5$ & $49.2 \pm 10.6$ \\
\hline \multirow{2}{*}{ All roots } & Coronal half & $36.3 \pm 17.0$ & $39.4 \pm 15.1$ \\
& Apical half & $40.3 \pm 22.8$ & $34.6 \pm 15.4$ \\
& Total canal & $38.3 \pm 19.2$ & $37.0 \pm 14.4$ \\
\hline
\end{tabular}




\section{Discussion}

Minimally invasive approaches to endodontics have only recently drawn the attention of the endodontic community at large $(6,9-11,120)$. These approaches have generated much controversial debate amid experts primarily based on opinion $(6,9,121-123)$. Mainstream endodontics has generally resisted minimally invasive approaches, possibly due to the added time required, challenges presented and absence of scientific evidence in support of the change $(6,121)$

To inform the emerging debate on the CEC concept, impacts associated with CEC designs in maxillary incisors and mandibular premolars and molars were recently reported (46). Improved fracture strength - a potential benefit - was reported in premolars and molars but not in the incisors, as well as compromised canal instrumentation efficacy - a potential risk - only in distal canals of mandibular molars (46). These findings suggested that the impacts of CEC varied for different tooth types (46). The unique morphology of maxillary molars warranted the present investigation into specific impacts of CEC in these teeth.

Mature, intact maxillary molars were used to avoid effects of varying degrees of tooth loss. Because collection of suitable teeth proved to be very challenging some of the teeth used were third molars. While matched for external dimensions when allocated to CEC and TEC groups, many teeth in both groups had fairly large pulp chambers and short roots, limiting the applicability of this study results to maxillary molars with similar characteristics. A sample size of 10 teeth per group has previously been found to be adequate for both instrumentation efficacy and fracture analysis using similar methodology (46). While blinding of the operator (BM) during experimentation was not possible, the standardized samples were allocated to separate groups preoperatively to minimize bias to the extent possible. 
Canals were instrumented with V-Taper2H instruments to pre-selected sizes (20/v06 in buccal canals and 30/v06 in palatal canals) regardless of clinical indications to minimize bias that may occur if specific sizes were selected for particular canals. Due to the regressive taper design of these instruments, the diameters $12 \mathrm{~mm}$ from the tip (D12) (0.64 $\mathrm{mm}$ and $0.74 \mathrm{~mm}$, respectively) are smaller than respective diameters of constant taper 20/04 and 20/06 instruments $(0.68 \mathrm{~mm}$ and $0.92 \mathrm{~mm}$, respectively) (Table 4). With smaller D12 dimensions, less removal of pericervical dentin was expected in both CEC and TEC groups than would occur with other instruments. In addition, V-Taper2H instruments are heat-treated; such treatment is expected to increase flexibility and resistance to cyclic fatigue compared to non-treated instruments (69). These characteristics were considered desirable in the absence of "convenience form" and straight-line pathways to canals. Indeed, no instrument fracture or ledge formation occurred in any of the teeth.

Instrumentation efficacy was assessed with higher resolution micro-CT imaging than in previous studies (46,89-91) to detect even subtle canal wall modification in light of the modestly-sized instruments. Thus, the higher resolution was used in effort to more accurately assess the MCW with a threshold of $1 \pm 1$ voxel, or $24 \mu \mathrm{m}$. During instrumentation, irrigation was carried out with only $2.5 \%$ sodium hypochlorite to standardize the sample and reflect most common clinical conditions (28).

Of several methods for axial strain or cuspal deflection analysis (62-64), strain gauges were chosen for their ability to detect minor changes in microstrain and their ease of use (63). This approach also allowed direct comparison within the same tooth of pre- and post-treatment axial microstrain $(63,64)$ (Fig. 3). Importantly, although forces in physiologic range $(50-150 \mathrm{~N})$ were 
applied to simulate chewing function (114), this assessment of axial strain may not reflect the complete strain pattern produced by the complex chewing process (114).

Endodontic cavities were restored with bonded composite resin to simulate clinical function and to facilitate loading. Filling of cavities with bonded composite resin may restore fracture strength of teeth to levels between $55 \%$ and $72 \%$ of the strength values of intact teeth (85). The restored molars were fatigued with cyclic loading to better simulate dentin fractures in root-filled teeth that are considered to be a fatigue process leading to micro-defects within tooth structure and at restoration-tooth interfaces $(103,104,113-115)$.

Fracture strength is a commonly studied, in-vitro surrogate measure of force at which tooth fracture occurs under continuously increasing compressive force. While this allows fracture strength comparisons and can suggest protocols more prone to failure, it has not been directly correlated with in-vivo outcomes (35-39); the latter should be verified with clinical testing. Nevertheless, efforts were made in this study to simulate clinical function of the sample, as previously mentioned, including both restoration of the endodontic cavity and cyclic loading $(103,104,113,115)$.

No significant difference in instrumentation efficacy was detected in the maxillary molars with CEC and TEC (Table 1). It was poor overall; instrumentation modified 49 to $59 \%$ of buccal canal walls and about $38 \%$ of palatal canal walls, corroborating the well-documented inability of engine-driven instruments to effectively contact canal walls in all tooth types (46), including maxillary molars $(89,90)$. Although the teeth in this study sample presented with rather wide canals relative to the modestly-sized instruments used for standardization, instrumentation efficacy was at par with previous reports in mandibular molars (46) accessed through CEC (52\% and $43 \%$ for mesial and distal canals, respectively) and through TEC (52\% and 63\% for mesial 
and distal canals, respectively), and only slightly below the reported range of 55 to $67 \%$ achieved through TEC in maxillary molars $(89,90)$. Contact of instruments with canal wall surface permits mechanical debridement of pulp tissue and disruption of bacterial biofilm $(24,26,27)$. The lack of detected compromise in instrumentation efficacy suggested no apparent risk in this regard in maxillary molars with CEC.

Axial microstrain data varied considerably without a discernible pattern in both CEC and TEC, supporting the second hypothesis (Table 2). Removal of dentin within the root canal increases deformation of the root (67) and loss of tooth structure increases strain in teeth $(65,66)$. Median relative stiffness values were calculated as previously described (64) (Fig. 4). The minimal change in axial microstrain recorded at the palatal root surfaces of maxillary molars from both groups and the greater microstrain changes at the mesio-buccal root surfaces, suggested that the mesio-buccal cusp was more prone to deformation after access and canal instrumentation than the relatively robust palatal cusp. The change in strain measured post-treatment noted at the mesio-buccal and palatal root surfaces might be explained by polymerization shrinkage effects of the bonded composite resin restoration of the endodontic cavity (101); the resulting contractile forces cause tensile strain (101) leading to increased tooth stiffness (102).

The magnitude of standard deviation for load-at-failure values (Table 3) was larger than was recorded in our similar study of mandibular molars (46), but consistent with other fracture studies of molar teeth $(74,86,119)$. The magnitude of standard deviation may be due to the natural morphological variation among maxillary molars and especially considering first, second and third molars were included in the sample. While many of the teeth were assumed to have been extracted due to periodontal reasons, the exact age of each tooth was unknown. Moreover, the teeth were inevitably subject to variable times in clinical function with varying patient- 
specific factors, such as bruxism or parafunction. As described, efforts were made to match specimens in each group of the sample.

No significant difference in fracture strength was detected in the restored maxillary molars with CEC and TEC (Fig. 6); in both groups it was lower than that of intact molars. The nonsignificant $23 \%$ increase in mean load-at-failure values for CEC compared to TEC was in sharp contrast to the $247 \%$ increase we previously reported for unrestored mandibular molars with CEC (46) and it did not elevate the fracture strength of maxillary molars with CEC to the level of intact molars as it did in mandibular molars (46). As no positive impact was detected in fracture strength of maxillary molars with CEC, it did not appear to offer a benefit in this regard.

Previously, fracture strength in mandibular molars with CEC restored with bonded composite resin was reported at $1480 \pm 76 \mathrm{~N}(68)$. This is slightly less than $1703 \pm 558 \mathrm{~N}$ reported herein for CEC similarly restored. Nevertheless, in the present study the lower fracture strength for both CEC and TEC compared to intact molars supported the use of cuspal or full coverage restorations to limit tooth structure deformation and possible fracture, as recommended for posterior endodontically treated teeth $(32,36,42,45,64,100)$.

Maxillary molars in both groups fractured in varying directions mesio-distally and buccopalatally (Fig. 7) with varying degrees of apical extent; no specific patterns were observed in either group.

Fracture strength of intact maxillary molars was reported at $4960 \pm 1147 \mathrm{~N}$ (119), approximately double the mean load-at-failure reported herein at $2457 \pm 941 \mathrm{~N}$. However, the stress was applied with a wider, $7.5 \mathrm{~mm}$ diameter cylinder (119) expected to require greater force to cause failure. Additionally, there was no description of the failure endpoint, which may have been the 
maximum force applied until fracture (119). In the present study, failure was defined as the point at which the continuously increasing compressive force dropped by at least $25 \%$, assumed to be a crack or fracture that was clinically significant (46). The mean load-at-failure for intact maxillary molars just below 2,500 $\mathrm{N}$ after cyclic fatiguing appeared higher than the $2029 \mathrm{~N}$ we reported for non-fatigued, intact mandibular molars (46). Though the comparison might not be appropriate because of use of cyclic fatiguing herein, the results suggested a higher fracture strength of intact maxillary molars, possibly due to a robust structure that might reduce the risk of fracture after endodontic treatment. Indeed, it has been observed that endodontically treated maxillary molars have a lower incidence of fracture than mandibular molars $(42,49,51)$.

Previous studies have highlighted the effects of lost coronal tooth structure on fracture strength and relative stiffness $(13,46,62,64)$ but the influence of endodontic cavity design on biomechanical properties has been found to vary depending on tooth type (46). The present study indicated there is no significant difference in fracture strength in maxillary molars with CEC or TEC. As described, we previously reported no differences for maxillary incisors irrespective of cavity design, and superior fracture strength in mandibular premolars and molars with CEC compared to TEC (46). Earlier research on TEC in maxillary second premolars suggested that the endodontic cavity did not influence relative stiffness as much as the loss of a marginal ridge with a Class 2 cavity (64). However, a recent finite element analysis (124) suggested that the endodontic cavity significantly undermined fracture strength in premolars, beyond that caused by a Class II cavity (124). Interestingly, the same study suggested that instrumentation of the root canal did not significantly influence fracture strength (124), calling into question previous claims regarding the importance of pericervical dentin (9-11). Preserving pericervical dentin in conjunction with minimally invasive endodontics has been promoted $(6,9-11)$ but clinical evidence of outcomes is deficient (11). While it has been well corroborated by several in-vitro 
studies that removal of coronal tooth structure impairs the tooth's overall strength $(13,46,68)$, future studies should explore the effects of instrumentation and removal of pericervical dentin in particular, a region critical for stress concentration $(67,103,125,126)$.

While minimally-invasive interventions have been embraced in some areas of dentistry (5), in endodontics the dentin-preserving CEC concept has been debated. Teeth requiring endodontic treatment, frequently having sustained various degrees of tooth structure loss, may particularly benefit from the tooth structure preserved by CEC; however, because CEC foregoes straight-line access and convenience form $(6,10)$ it poses challenges not encountered if TEC is used (52). The availability of operating microscopes and improved NiTi instruments, both facilitating treatment with less convenience form, has promoted recommendations to use CEC as a routine approach $(6,10)$. Whether clinicians should strive to adapt their skills for routine use of CEC should depend on demonstrated clinical benefits, such as lower fracture rates without compromised healing rates. Until appropriate clinical evidence is available, in-vitro research can only suggest benefits and risks but should not be used as basis for revision of clinical guidelines for endodontic cavities. The current in-vitro study neither supported an apparent biomechanical benefit nor instrumentation efficacy risk associated with CEC in maxillary molars. These findings were in line with our previous observations in maxillary incisors (46) and different from those in mandibular molars (46). Considering that maxillary molars present with particularly challenging root canal systems in the mesio-buccal roots, where secondary canals are difficult to locate and negotiate (127), the application of CEC in these teeth merits careful consideration. 


\section{Conclusion}

Within the limitations of in-vitro testing, CEC in maxillary molars did not appear to impact instrumentation efficacy compared to TEC, as no significant differences were detected in proportion of $\mathrm{MCW}$ in root canals. $\mathrm{CEC}$ also did not appear to impact biomechanical responses compared to TEC, as no significant differences were detected in fracture strength under continuously increasing compressive load. 


\section{References}

1. Mack MJ. Minimally invasive and robotic surgery. J Am Med Assoc 2001;285:568-72.

2. Smith Z, Fessler RG. Paradigm changes in spine surgery: evolution of minimally invasive techniques. Nat Rev Neurol 2012;8:443-50.

3. Kwon DS, Chang GJ. The role of minimally invasive surgery and outcomes in colorectal cancer. Perm J 2011;15:61-6.

4. Oh S-Y, Kwon S, Lee K-G, Suh Y-S, Choe H-N, Kong S-H, et al. Outcomes of minimally invasive surgery for early gastric cancer are comparable with those for open surgery: analysis of 1,013 minimally invasive surgeries at a single institution. Surg Endosc 2014;28:789-95.

5. Murdoch-Kinch CA, McLean ME. Minimally invasive dentistry. J Am Dent Assoc 2003;134:87-95.

6. Bóveda C, Kishen A. Contracted endodontic cavities: the foundation for less invasive alternatives in the management of apical periodontitis. Endod Top 2015;33:169-86.

7. Black G. Operative Dentistry. 7th ed. Chicago: Medico-Dental Publishing; 1936.

8. Schwendicke F, Frencken JE, Bjorndal L, Maltz M, Manton DJ, Ricketts D, et al. Managing carious lesions: Consensus recommendations on carious tissue removal. Adv Dent Res 2016;28:58-67.

9. Clark D, Khademi J, Herbranson E. The new science of strong endo teeth. Dent Today 2013;32:112-7.

10. Clark D, Khademi J. Modern molar endodontic access and directed dentin conservation. Dent Clin North Am 2010;54:249-73.

11. Clark D, Khademi J. Case studies in modern molar endodontic access and directed dentin conservation. Dent Clin North Am 2010;54:275-89.

12. Nagasiri R, Chitmongkolsuk S. Long-term survival of endodontically treated molars 
without crown coverage: A retrospective cohort study. J Prosthet Dent 2005;93:164-70.

13. Assif D, Nissan J, Gafni Y, Gordon M. Assessment of the resistance to fracture of endodontically treated molars restored with amalgam. J Prosthet Dent 2003;89:462-5.

14. Endodontic facts [Internet]. [cited 2016 May 18]. Available from: http://www.aae.org/about-aae/news-room/endodontic-facts.aspx

15. Pak JG, Fayazi S, White SN. Prevalence of periapical radiolucency and root canal treatment: a systematic review of cross-sectional studies. J Endod 2012;38:1170-6.

16. Dugas NN, Lawrence HP, Teplitsky P, Friedman S. Quality of life and satisfaction outcomes of endodontic treatment. J Endod 2002;28:819-27.

17. Kakehashi S, Stanley HR, Fitzgerald RJ. The effects of surgical exposures of dental pulps in germ-free and conventional laboratory rats. Oral Surg Oral Med Oral Pathol $1965 ; 20: 340-9$.

18. Silva TA, Garlet GP, Fukada SY, Silva JS, Cunha FQ. Chemokines in oral inflammatory diseases: apical periodontitis and periodontal disease. J Dent Res 2007;86:306-19.

19. Sutherland S, Matthews DC. Emergency management of acute apical periodontitis in the permanent dentition: a systematic review of the literature. J Can Dent Assoc 2003;69:160.

20. Ørstavik D, Ford TP. Apical periodontitis: microbial infection and host responses. In: Essential endodontology Prevention and treatment of apical periodontitis. Oxford: Blackwell Science; 1998. p. 1-9.

21. Nagaoka S, Miyazaki Y, Liu HJ, Iwamoto Y, Kitano M, Kawagoe M. Bacterial invasion into dentinal tubules of human vital and nonvital teeth. J Endod 1995;21:70-3.

22. Peters L, Wesselink P, Moorer W. The fate and the role of bacteria left in root dentinal tubules. Int Endod J 1995;28:95-9.

23. Peters L, Wesselink P, Buijs J, van Winkelhoff A. Viable bacteria in root dentinal tubules of teeth with apical periodontitis. J Endod 2001;27:76-81. 
24. Haapasalo M, Endal U, Zandi H, Coil JM. Eradication of endodontic infection by instrumentation and irrigation solutions. Endod Top 2005;10:77-102.

25. Ingle J. Endodontic cavity preparation. In: Ingle J, Tamber J, editors. Endodontics. 3rd ed. Philadelphia: Lea \& Febiger; 1985. p. 102-67.

26. Bystrom A, Sundqvist G. Bacteriologic evaluation ofthe efficacy of mechanical root canal instrumentation in endodontic therapy. Scand J Dent Res 1981;89:321-8.

27. Lin J, Shen Y, Haapasalo M. A comparative study of biofilm removal with hand, rotary nickel-titanium, and self-adjusting file instrumentation using a novel in vitro biofilm model. J Endod 2013;39:658-63.

28. Bystrom A, Sundqvist G. The antibacterial action of sodium hypochlorite and EDTA in 60 cases of endodontic therapy. Int Endod J 1985;18:35-40.

29. Schilder H. Filling root canals in three dimensions. Dent Clin North Am 1967;32:723-31.

30. Ree M, Schwartz RS. The endo-restorative interface: current concepts. Dent Clin North Am 2010;54:345-74.

31. Schwartz RS, Robbins JW. Post placement and restoration of endodontically treated teeth: a literature review. J Endod 2004;30:289-301.

32. Baba NZ, Goodacre CJ. Restoration of endodontically treated teeth : contemporary concepts and future perspectives. Endod Top 2014;31:68-83.

33. Azarpazhooh A, Quiñonez C. Treatment Preferences for Toothache Among Working Poor Canadians. J Endod 2015;41:1985-90.

34. Azarpazhooh A, Dao T, Figueiredo R, Krahn M, Friedman S. A survey of patients' preferences for the treatment of teeth with apical periodontitis. J Endod 2013;39:1534-41.

35. Ng Y-L, Mann V, Gulabivala K. A prospective study of the factors affecting outcomes of non-surgical root canal treatment: part 2: tooth survival. Int Endod J 2011;44:610-25.

36. Borén DL, Jonasson P, Kvist T. Long-term survival of endodontically treated teeth at a 
public dental specialist clinic. J Endod 2015;41:176-81.

37. Fransson H, Dawson VS, Frisk F, Bjørndal L, Kvist T. Survival of root-filled teeth in the swedish adult population. J Endod 2016;42:216-20.

38. Ng YL, Mann V, Gulabivala K. A prospective study of the factors affecting outcomes of nonsurgical root canal treatment: Part 1: Periapical health. Int Endod J 2011;44:583-609.

39. de Chevigny C, Dao TT, Basrani BR, Marquis V, Farzaneh M, Abitbol S, Friedman S. Treatment outcome in endodontics: the Toronto study-phase 4: initial treatment. J Endod 2008;34:258-63.

40. Ørstavik D, Kerekes K, Eriksen H. The periapical index: A scoring system for radiographic assesment of apical periodontitis. Endod Dent Traumatol 1986;2:20-34.

41. Fonzar F, Fonzar A, Buttolo P, Worthington H V, Esposito M. The prognosis of root canal therapy: a 10-year retrospective cohort study on 411 patients with 1175 endodontically treated teeth. Eur J Oral Implantol 2009;2:201-8.

42. Zadik Y, Sandler V, Bechor R, Salehrabi R. Analysis of factors related to extraction of endodontically treated teeth. Oral Surg Oral Med Oral Pathol Oral Radiol Endod 2008;106:31-5.

43. Caplan DJ, Weintraub J. Factors related to loss of root canal filled teeth. J Public Health Dent 1997;57:31-9.

44. Aquilino SA, Caplan DJ. Relationship between crown placement and the survival of endodontically treated teeth. J Prosthet Dent 2002;87:256-63.

45. Tang W, Wu Y, Smales RJ. Identifying and reducing risks for potential fractures in endodontically treated teeth. J Endod 2010;36:609-17.

46. Krishan R, Paqué F, Ossareh A, Kishen A, Dao T, Friedman S. Impacts of conservative endodontic cavity on root canal instrumentation efficacy and resistance to fracture assessed in incisors, premolars, and molars. J Endod 2014;40:1160-6. 
47. Tzimpoulas NE, Alisafis MG, Tzanetakis GN, Kontakiotis EG. A prospective study of the extraction and retention incidence of endodontically treated teeth with uncertain prognosis after endodontic referral. J Endod 2012;38:1326-9.

48. Kang SH, Kim BS, Kim Y. Cracked Teeth: Distribution, Characteristics, and Survival after Root Canal Treatment. J Endod 2016;42:557-62.

49. Tamse A, Fuss Z, Lustig J, Kaplavi J. An evaluation of endodontically treated vertically fractured teeth. J Endod 1999;25:506-8.

50. Kaldahl W, Becker C, Wentz F. Periodontal surgical preparation for specific problems in restorative dentistry. J Prosthet Dent 1984;51:36-41.

51. Vire DE. Failure of endodontically treated teeth: classification and evaluation. J Endod $1991 ; 17: 338-42$.

52. Goerig AC, Michelich RJ, Schultz HH. Instrumentation of root canals in molar using the step-down technique. J Endod 1982;8:550-4.

53. Castellucci A. Access cavity and endodontic anatomy. In: Endodontics. Firenze: Il Tridente; 2005. p. 244-329.

54. Schroeder KP, Walton RE, Rivera EM. Straight line access and coronal flaring: effect on canal length. J Endod 2002;28:474-6.

55. Weine FS, Kelly RF, Lio PJ. The effect of preparation procedures on original canal shape and on apical foramen shape. J Endod 1975;1:255-62.

56. Greene KJ, Krell K V. Clinical factors associated with ledged canals in maxillary and mandibular molars. Oral Surg Oral Med Oral Pathol 1990;70:490-7.

57. Bürklein S, Schäfer E. Critical evaluation of root canal transportation by instrumentation. Endod Top 2013;29:110-24.

58. Lin LM, Rosenberg PA, Lin J. Do procedural errors cause endodontic treatment failure? J Am Dent Assoc 2005;136:187-93. 
59. Kapalas A, Lambrianidis T. Factors associated with root canal ledging during instrumentation. Endod Dent Traumatol 2000;16:229-31.

60. Gambill JM, Alder M, del Rio CE. Comparison of nickel-titanium and stainless steel hand-file instrumentation using computed tomography. J Endod 1996;22:369-75.

61. Schäfer E, Schulz-Bongert U, Tulus G. Comparison of hand stainless steel and nickel titanium rotary instrumentation: a clinical study. J Endod 2004;30:432-5.

62. Panitvisai P, Messer H. Cuspal deflection in molars in relation to endodontic and restorative procedures. J Endod 1995;21:57-61.

63. Jantarat J, Panitvisai P, Palamara JE, Messer HH. Comparison of methods for measuring cuspal deformation in teeth. J Dent 2001;29:75-82.

64. Reeh ES, Messer HH, Douglas WH. Reduction in tooth stiffness as a result of endodontic and restorative procedures. J Endod 1989;15:512-6.

65. Soares PV, Santos-Filho PCF, Gomide HA, Araujo CA, Martins LRM, Soares CJ. Influence of restorative technique on the biomechanical behavior of endodontically treated maxillary premolars. Part II: Strain measurement and stress distribution. J Prosthet Dent 2008;99:114-22.

66. Pereira J, McDonald A, Petrie A, Knowles J. Effect of cavity design on tooth surface strain. J Prosthet Dent 2013;110:369-75.

67. Lang H, Korkmaz Y, Schneider K, Raab WH-M. Impact of endodontic treatments on the rigidity of the root. J Dent Res 2006;85:364-8.

68. Al Amri MD, Al-Johany S, Sherfudhin H, Al Shammari B, Al Mohefer S, Al Saloum M, et al. Fracture resistance of endodontically treated mandibular first molars with conservative access cavity and different restorative techniques: An in vitro study. Aust Endod J 2016;1-8.

69. Shen Y, Zhou H, Zheng Y, Campbell L, Peng B, Haapasalo M. Metallurgical characterization of controlled memory wire nickel-titanium rotary instruments. J Endod 
2011;37:1566-71.

70. Plotino G, Testarelli L, Al-Sudani D, Pongione G, Grande NM, Gambarini G. Fatigue resistance of rotary instruments manufactured using different nickel-titanium alloys: A comparative study. Odontology 2014;102:31-5.

71. Shen Y, Zhou HM, Zheng YF, Peng B, Haapasalo M. Current challenges and concepts of the thermomechanical treatment of nickel-titanium instruments. J Endod 2013;39:163-72.

72. Sorensen JA, Martinoff JT. Intracoronal reinforcement and coronal coverage: A study of endodontically treated teeth. J Prosthet Dent 1984;51:780-4.

73. Re GJ, Norling BK. Fracturing molars with axial forces. J Dent Res 1981;60:805-8.

74. Watts D, El Mowafy O, Grant A. Fracture resistance of lower molars with class 1 composite and amalgam restorations. Dent Mater 1987;3:261-4.

75. Combe EC, Shaglouf AM, Watts DC, Wilson NH. Mechanical properties of direct core build-up materials. Dent Mater 1999;15:158-65.

76. Craig R, Peyton F. Elastic and mechanical properties of human dentin. J Dent Res 1958;37:710-8.

77. Scholtanus JD, Özcan M, Huysmans M. Penetration of amalgam constituents into dentine. J Dent 2009;37:366-73.

78. Woods JS, Martin MD, Leroux BG. Biomarkers of kidney integrity in children and adolescents with dental amalgam mercury exposure: Findings from the Casa Pia children's amalgam trial. J Esthet Restor Dent 2013;25:436-7.

79. Roulet J. Benefits and disadvantages of tooth coloured alternatives. J Dent 1997;25:45973.

80. Abe Y, Lambrechts P, Inoue S, Braem MJA, Takeuchi M, Vanherle G, et al. Dynamic elastic modulus of "packable" composites. Dent Mater 2001;17:520-5.

81. Ho CT, Vijayaraghavan T V, Lee SY, Tsai A, Huang HM, Pan LC. Flexural behaviour of 
post-cured composites at oral-simulating temperatures. J Oral Rehabil 2001;28:658-67.

82. Kugel G, Ferrari M. The science of bonding: from first to sixth generation. J Am Dent Assoc 2009;131:20S - 25S.

83. Hofmann N, Just N, Hugo B, Haller B. The effect of glass ionomer cement or composite resin bases on restoration of cuspal stiffness of endodontically treated premolars in vitro. Clin Oral Investig 1998;2:77-83.

84. Moezizadeh M, Mokhtari N. Fracture resistance of endodontically treated premolars with fibre-reinforced composite restorations. J Conserv Dent 2011;14:277-81.

85. Hamouda IM, Shehata SH. Fracture resistance of posterior teeth restored with modern restorative materials. J Biomed Res 2011;25:418-24.

86. Plotino G, Buono L, Grande NM, Lamorgese V, Somma F. Fracture resistance of endodontically treated molars restored with extensive composite resin restorations. J Prosthet Dent 2008;99:225-32.

87. Liu Y, Tjäderhane L, Breschi L, Mazzoni A, Li N, Mao J, et al. Limitations in bonding to dentin and experimental strategies to prevent bond degradation. J Dent Res 2011;90:95368.

88. Saber S, Nagy M, Schafer E. Comparative evaluation of the shaping ability of ProTaper Next, iRaCe and Hyflex CM rotary NiTi files in severely curved root canals. Int Endod J 2015;48:131-6.

89. Peters O, Laib A, Göhring T, Barbakow F. Changes in root canal geometry after preparation assessed by high-resolution computed tomography. J Endod 2001;27:1-6.

90. Peters O, Peters C, Schönenberger K, Barbakow F, Scho K. ProTaper rotary root canal preparation: effects of canal anatomy on final shape analysed by micro CT. Int Endod J 2003;36:86-92.

91. Paqué F, Ganahl D, Peters O. Effects of root canal preparation on apical geometry assessed by micro-computed tomography. J Endod 2009;35:1056-9. 
92. Roggendorf MJ, Legner M, Ebert J, Fillery E, Frankenberger R, Friedman S. Micro-CT evaluation of residual material in canals filled with Activ GP or GuttaFlow following removal with NiTi instruments. Int Endod J 2010;43:200-9.

93. Bjørndal L, Carlsen O, Thuesen G, Darvann T, Kreiborg S. External and internal macromorphology in 3D-reconstructed maxillary molars using computerized X-ray microtomography. Int Endod J 1999;32:3-9.

94. Moore J, Fitz-Walter P, Parashos P. A micro-computed tomographic evaluation of apical root canal preparation using three instrumentation techniques. Int Endod J 2009;42:105764.

95. Mader CL, Baumgartner JC, Peters DD. Scanning electron microscopic investigation of the smeared layer on root canal walls. J Endod 1984;10:477-83.

96. Parente J, Loushine R, Susin L, Gu L, Looney S, Weller R, et al. Root canal debridement using manual dynamic agitation or the EndoVac for final irrigation in a closed system and an open system. Int Endod J 2010;43:1001-12.

97. Marin J. Mechanical behavior of engineering materials. Prentice-Hall; 1962.

98. Witt GR. The electromechanical properties of thin films and the thin film strain gauge. Thin Solid Films 1974;22:133-56.

99. Wiśniewski Z, Wiśniewski R, Nowiński JL. Application of foil strain gauges in high pressure research. Rev Sci Instrum 2001;72:2829-31.

100. Linn J, Messer HH. Effect of restorative procedures on the strength of endodontically treated molars. J Endod 2010;20:479-85.

101. Meredith N, Setchell DJ. In vitro measurement of cuspal strain and displacement in composite restored teeth. J Dent 1997;25:331-7.

102. Morin DL, Cross M, Voller VR, Douglas WH, DeLong R. Biophysical stress analysis of restored teeth: modelling and analysis. Dent Mater 1988;4:77-84. 
103. Kishen A. Mechanisms and risk factors for fracture predilection in endodontically treated teeth. Endod Top 2006;17:57-83.

104. Kishen A, Kumar G V, Chen N-N. Stress-strain response in human dentine: rethinking fracture predilection in postcore restored teeth. Dent Traumatol 2004;20:90-100.

105. Craig RG, Peyton FA, Johnson DW. Compressive properties of enamel, dental cements, and gold. J Dent Res 1961;40:936-45.

106. Helfer A, Melnick S, Schilder H. Determination of the moisture content of vital and pulpless teeth. Oral Surg 1972;34:661-70.

107. Kishen A, Vedantam S. Hydromechanics in dentine: Role of dentinal tubules and hydrostatic pressure on mechanical stress-strain distribution. Dent Mater 2007;23:1296306.

108. Papa J, Cain C, Messer HH. Moisture content of vital vs endodontically treated teeth. Endod Dent Traumatol 1994;10:91-3.

109. Sedgley C, Messer H. Are endodontically treated teeth more brittle? J Endod $1992 ; 18: 332-5$.

110. Huang TJ, Schilder H, Nathanson D. Effects of moisture content and endodontic treatment on some mechanical properties of human dentin. J Endod 1992;18:209-15.

111. Shemesh H. Endodontic instrumentation and root filling procedures: effect on mechanical integrity of dentin. Endod Top 2015;33:43-9.

112. Barreto MS, Moraes RDA, Rosa RA Da, Moreira CHC, Só MVR, Bier CAS. Vertical root fractures and dentin defects: effects of root canal preparation, filling, and mechanical cycling. J Endod 2012;38:1135-9.

113. Nalla RK, Imbeni V, Kinney JH, Staninec M, Marshall SJ, Ritchie RO. In vitro fatigue behavior of human dentin with implications for life prediction. J Biomed Mater Res $2003 ; 66: 10-20$. 
114. De Boever JA, McCall Jr WD, Holden S, Ash Jr MM. Functional occlusal forces: An investigation by telemetry. J Prosthet Dent 1978;40:326-33.

115. DeLong R, Sakaguchi RL, Douglas WH, Pintado MR. The wear of dental amalgam in an artificial mouth: a clinical correlation. Dent Mater 1985;1:238-42.

116. Rippe MP, Santini MF, Souza Bier CA, Baldissara P, Valandro LF. Effect of root canal preparation, type of endodontic post and mechanical cycling on root fracture strength. $\mathrm{J}$ Appl Oral Sci 2014;22:165-73.

117. Studart AR, Filser F, Kocher P, Gauckler LJ. In vitro lifetime of dental ceramics under cyclic loading in water. Biomaterials 2007;28:2695-705.

118. Re GJ, Norling BK, Draheim N. Fracture strength of molars containing three surface amalgam restorations. J Prosthet Dent 1982;185-7.

119. Rodrigues FB, Paranhos MPG, Spohr AM, Oshima HMS, Carlini B, Burnett LH. Fracture resistance of root filled molar teeth restored with glass fibre bundles. Int Endod J 2010;43:356-62.

120. Peters OA, Arias A, Paqué F. A micro-computed tomographic assessment of root canal preparation with a novel instrument, TRUShape, in mesial roots of mandibular molars. J Endod 2015;41:1545-50.

121. Ruddle CJ. Endodontic triad for success: The role of minimally invasive technology. Dent Today 2015;May:1-7.

122. Ruddle CJ. Access preparation. Dent Today 2007;Feb:1-7.

123. Gluskin AH, Peters CI, Peters OA. Minimally invasive endodontics: challenging prevailing paradigms. Nat Publ Gr 2014;216:347-53.

124. Zelic K, Vukicevic A, Jovicic G, Aleksandrovic S, Filipovic N, Djuric M. Mechanical weakening of devitalized teeth : three-dimensional Finite Element Analysis and prediction of tooth fracture. Int Endod J 2015;850-63. f 
125. Rundquist BD, Versluis A. How does canal taper affect root stresses? Int Endod J 2006;39:226-37.

126. Ng CCH, Dumbrigue HB, Al-Bayat MI, Griggs JA, Wakefield CW. Influence of remaining coronal tooth structure location on the fracture resistance of restored endodontically treated anterior teeth. J Prosthet Dent 2006;95:290-6.

127. Görduysus M, Görduysus M, Friedman S. Operating microscope improves negotiation of second mesiobuccal canals in maxillary molars. J Endod 2001;27:683-6. 


\section{Figures}

Fig. 1. The two access cavity designs used in this study. A. Contracted (CEC). B. Traditional (TEC).
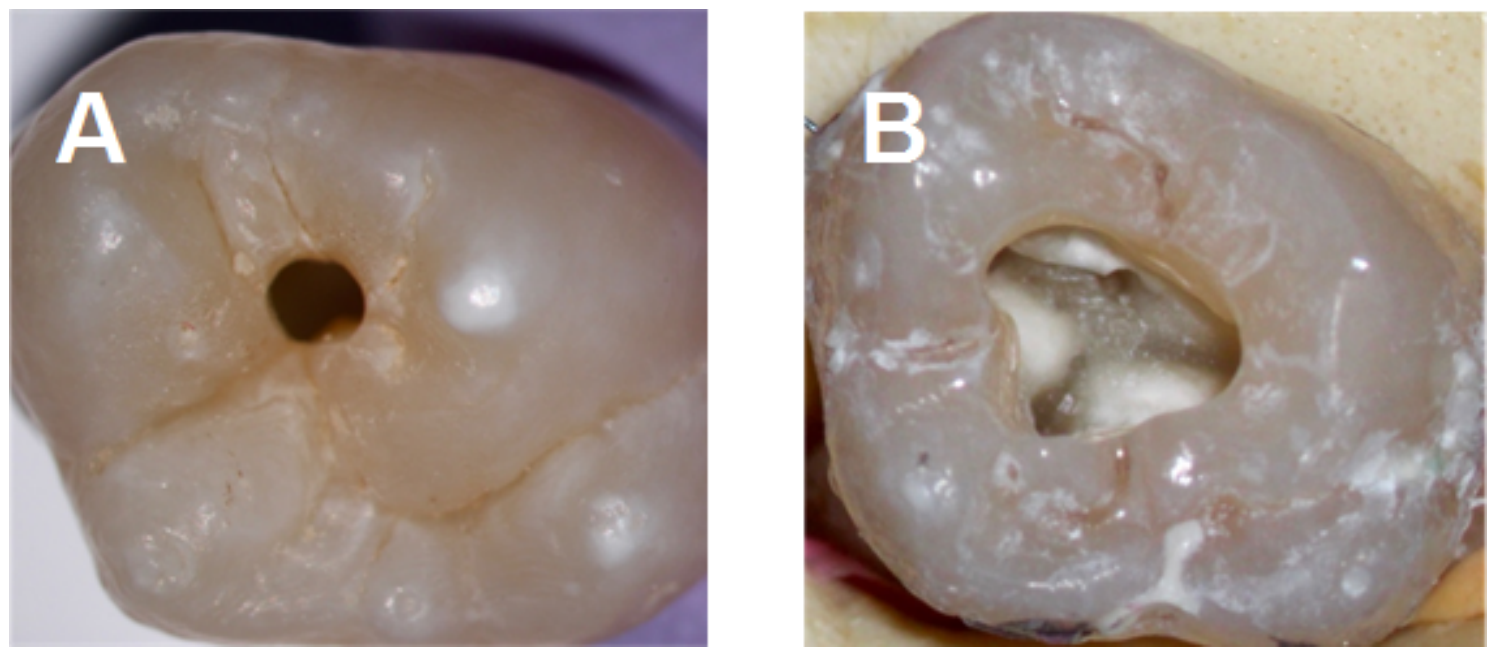

Fig. 2. 3D reconstructed super-imposed micro-CT images of instrumented (yellow) and original root canals (red) of maxillary molars with Left: contracted (CEC) and Right: traditional (TEC) access. Yellow areas represent modified canal walls.
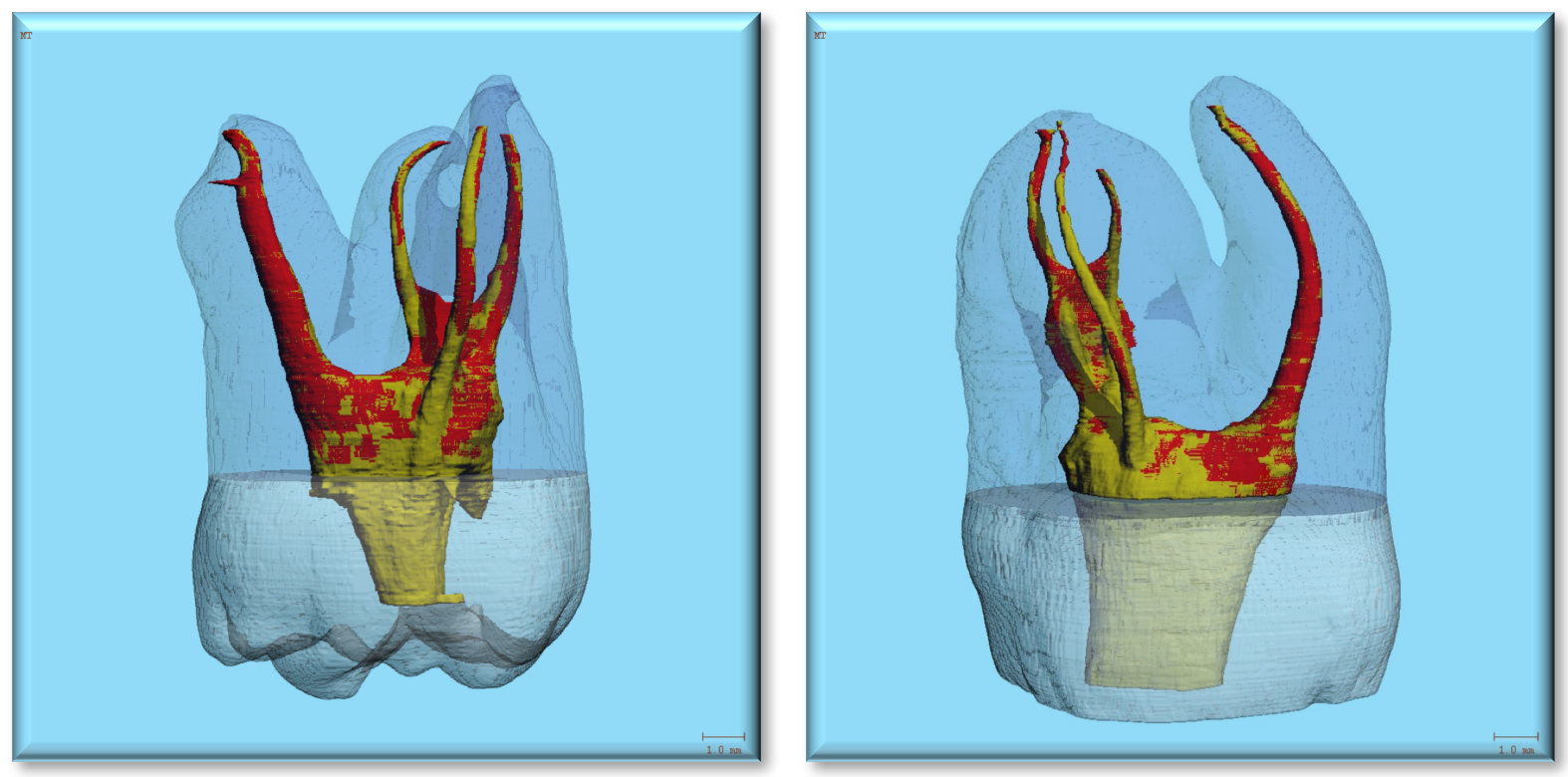
Fig. 3. Axial microstrain measured at mesio-buccal and palatal cervical root surfaces of a maxillary molar under simulated physiologic loads (50-150 N) in the Instron Universal Testing machine. Measurements were obtained before access (pre-op) and after contracted (CEC) access, canal instrumentation and bonded composite resin restoration (post-op). While the pre- and postop measurements at the palatal surface were similar, the measurements at the mesio-buccal surface changed from compressive microstrain pre-op, to tensile microstrain post-op.

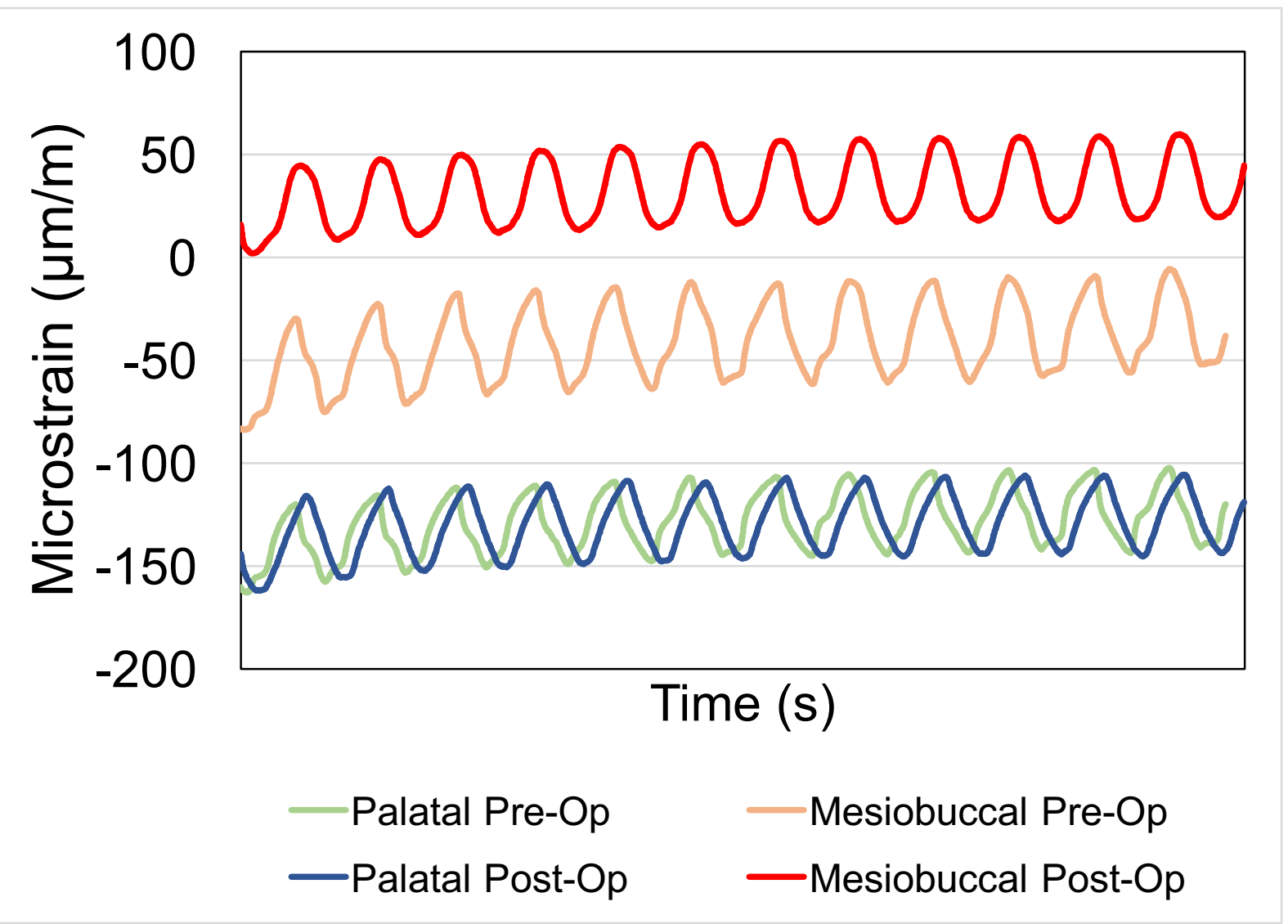


Fig. 4. Median values of relative stiffness measured at mesio-buccal and palatal cervical surfaces of maxillary molars with restored contracted (CEC) or traditional (TEC) access, under simulated physiologic loads (50-150 N) in the Instron Universal Testing machine.

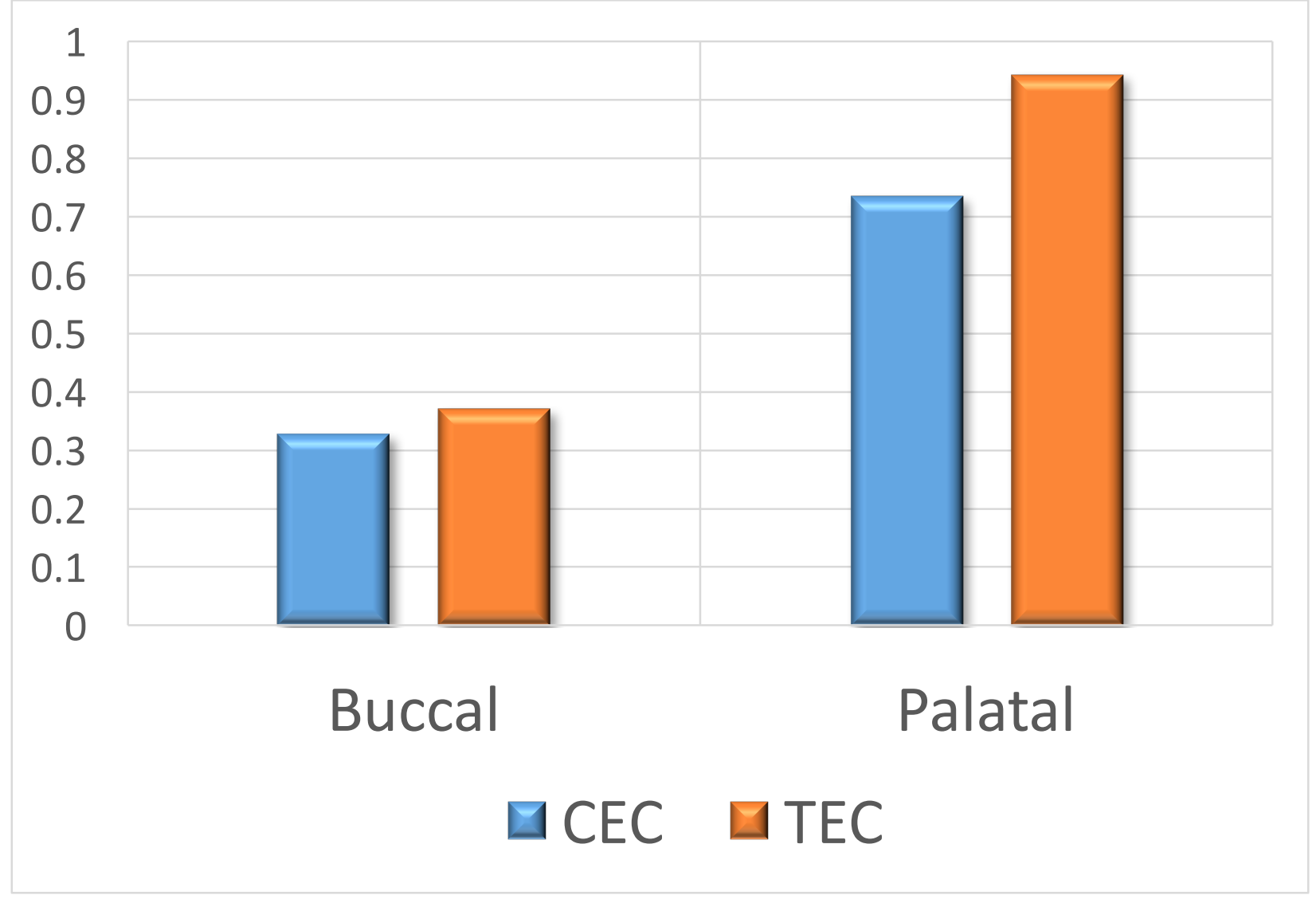


Fig. 5. Load-at-failure (N) recorded in restored A) contracted (CEC) cavity and B) traditional (TEC) cavity, under continuous compressive load preceded by 1 million cycles of fatiguing in the Instron Universal Testing machine.
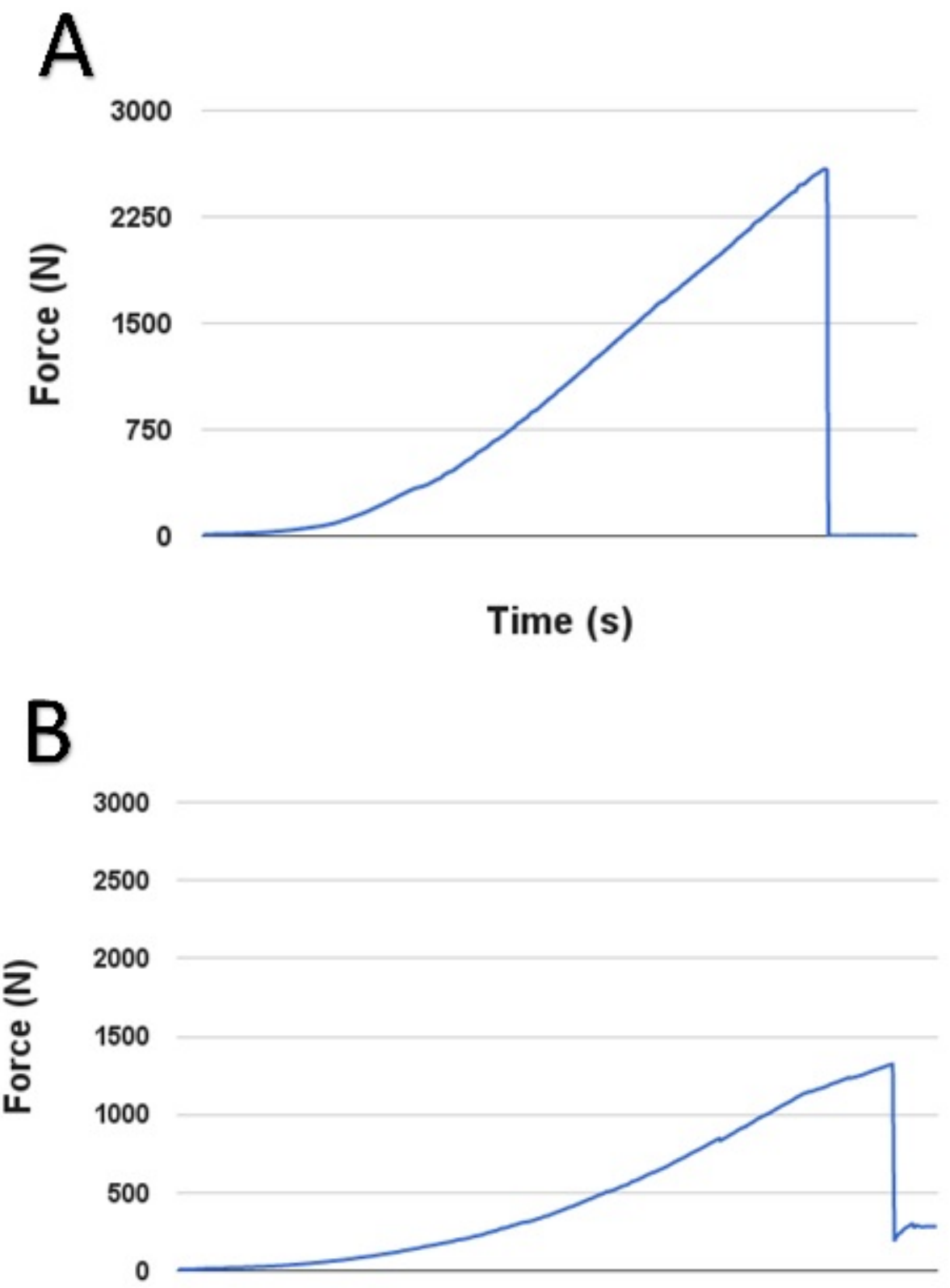

Time (s) 
Fig. 6. Mean load-at-failure in maxillary molars, intact (control) or with restored contracted (CEC) or traditional (TEC) access, under compressive load preceded by 1 million cycles of fatiguing loads in the Instron Universal Testing machine.

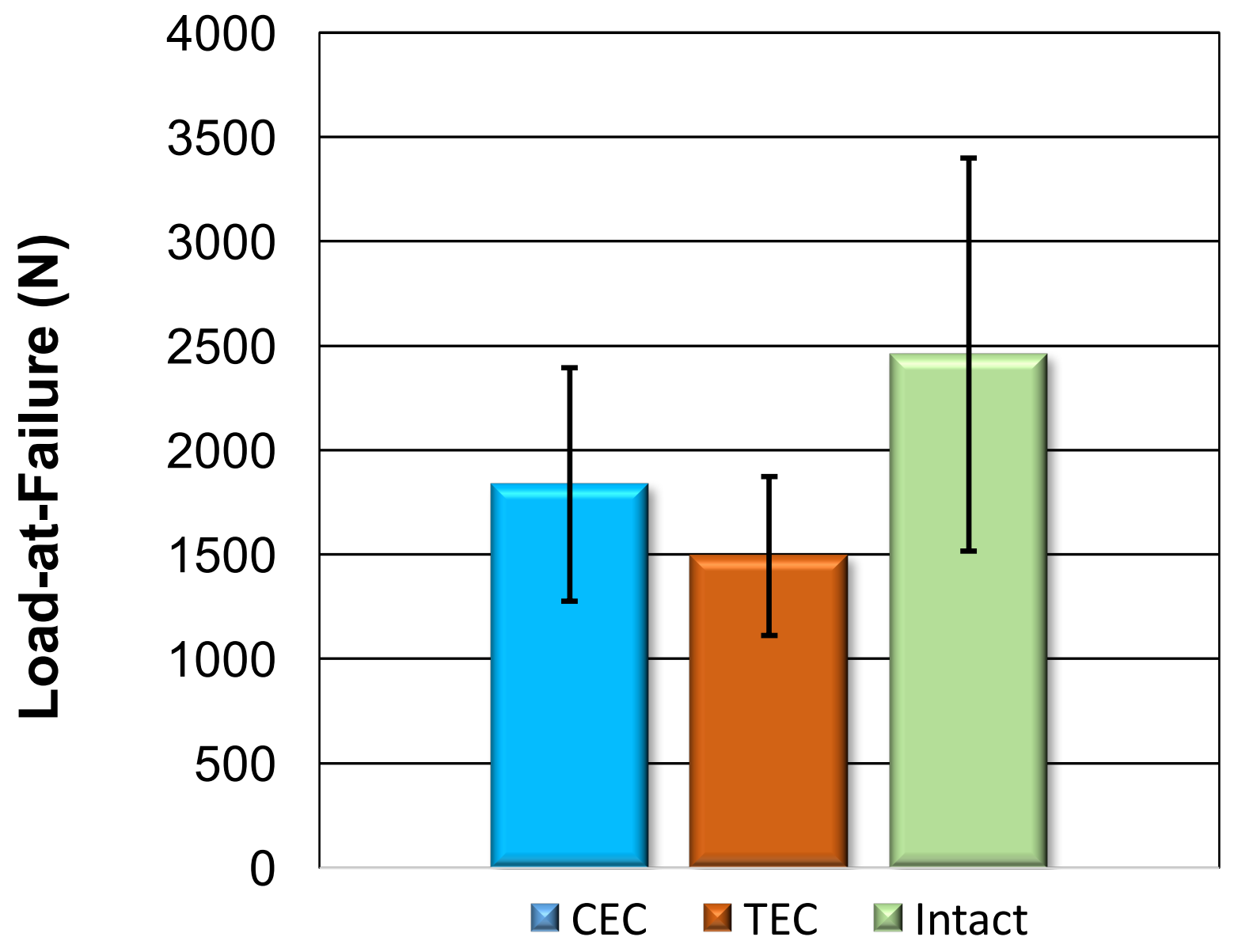


Fig. 7. Examples of Fractured specimens A. contacted (CEC) and B. traditional (TEC)
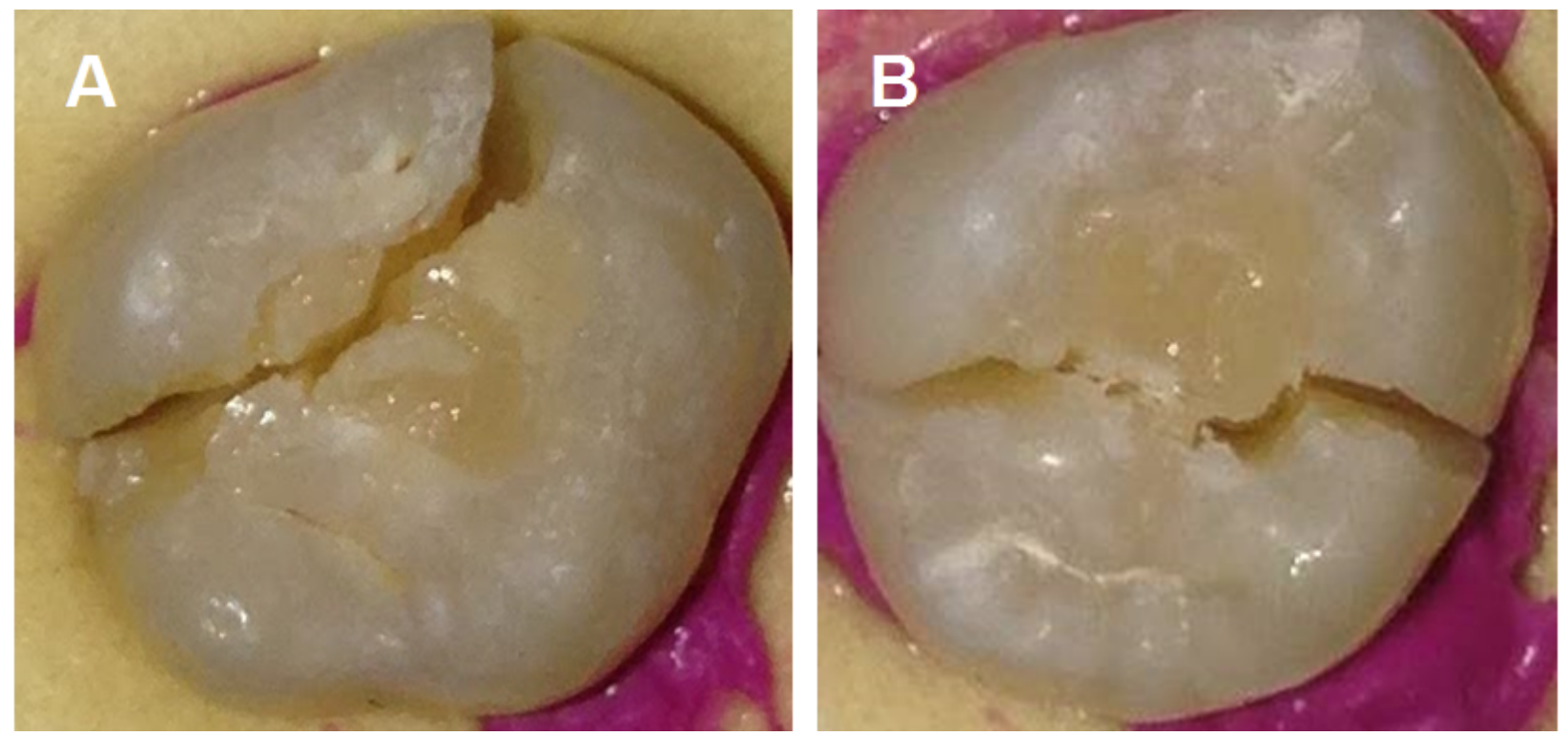


\section{Tables}

Table 1. Modified Canal Wall (MCW; mean and standard deviation) after instrumentation in maxillary molars performed through contracted (CEC) or traditional (TEC) access, assessed by micro-CT. MCW is expressed as proportion of the total canal wall area; mean and standard deviation values presented by coronal and apical halves of the three roots.

\begin{tabular}{|l|l|c|c|}
\hline \multirow{2}{*}{$\begin{array}{c}\text { Root } \\
(\mathrm{n}=9)\end{array}$} & Assessed canal level & \multicolumn{2}{|c|}{$\begin{array}{c}\text { Modified Canal Wall } \\
\text { (\% of total canal wall surface })\end{array}$} \\
\cline { 3 - 4 } Mesio-buccal & Coronal half & $57.1 \pm 18.2$ & TEC \\
& Apical half & $49.2 \pm 10.1$ & $54.3 \pm 17.0$ \\
& Total canal & $53.1 \pm 11.6$ & $45.1 \pm 18.6$ \\
& Coronal half & $59.7 \pm 16.8$ & $49.7 \pm 16.5$ \\
\hline \multirow{3}{*}{ Disto-buccal } & Apical half & $58.3 \pm 14.4$ & $51.6 \pm 12.2$ \\
& Total canal & $59.0 \pm 14.5$ & $46.7 \pm 9.8$ \\
& Coronal half & $36.3 \pm 17.0$ & $49.2 \pm 10.6$ \\
\hline Palatal & Apical half & $40.3 \pm 22.8$ & $39.4 \pm 15.1$ \\
& Total canal & $38.3 \pm 19.2$ & $34.6 \pm 15.4$ \\
\hline All roots & Total & $49.7 \pm 12.0$ & $37.0 \pm 14.4$ \\
\hline
\end{tabular}


Table 2. Axial microstrain values in maxillary molars with contracted cavity (CEC) and traditional cavity (TEC), measured at mesio-buccal and palatal root surfaces under simulated physiologic loads (50-150 N) in the Instron Universal Testing machine. Measurements were obtained before access (Intact tooth) and after endodontic cavity, canal instrumentation and bonded composite resin restoration (Post-treatment).

\begin{tabular}{|c|c|c|c|c|}
\hline \multirow{3}{*}{ Specimen } & \multicolumn{4}{|c|}{ Mean Axial Strain $(\mu \mathrm{m})$} \\
\hline & \multicolumn{2}{|c|}{ Intact tooth } & \multicolumn{2}{|c|}{ Post-treatment } \\
\hline & Mesio-buccal & Palatal & Mesio-buccal & Palatal \\
\hline \multicolumn{5}{|l|}{ CEC } \\
\hline 1 & -41.2 & -129.0 & 32.1 & -130.0 \\
\hline 2 & 115.7 & -63.7 & -87.5 & -51.0 \\
\hline 3 & -111.1 & -57.7 & 307.9 & -45.8 \\
\hline 4 & -143.8 & -238.1 & -159.8 & -240.8 \\
\hline 5 & -26.1 & -14.7 & -4.6 & 20.0 \\
\hline 6 & 69.3 & 52.3 & 4.6 & -15.3 \\
\hline 7 & -474.8 & -25.4 & -69.7 & -158.2 \\
\hline 8 & -70.2 & -39.7 & 24.7 & 22.8 \\
\hline 9 & -106.6 & -9.8 & -180.8 & -257.0 \\
\hline 10 & -8.8 & -103.4 & 17.2 & -184.4 \\
\hline 11 & 92.2 & -101.6 & 50.3 & -65.7 \\
\hline 12 & -4.9 & -62.6 & -75.7 & -68.9 \\
\hline \multicolumn{5}{|l|}{ TEC } \\
\hline 1 & -9.0 & -60.0 & 50.3 & -7.8 \\
\hline 2 & -36.7 & -94.2 & -137.8 & -151.2 \\
\hline 3 & -104.4 & no data & -64.7 & no data \\
\hline 4 & -133.8 & -26.6 & -163.0 & 2.2 \\
\hline 5 & 13.0 & -20.9 & -223.0 & 6.6 \\
\hline 6 & -122.2 & -191.2 & -78.6 & -4.5 \\
\hline 7 & -11.8 & -57.5 & 29.1 & -50.8 \\
\hline 8 & -15.8 & -59.7 & -9.4 & -55.1 \\
\hline 9 & -15.7 & -303.3 & -20.1 & -277.9 \\
\hline 10 & -17.3 & -179.5 & -36.3 & -190.5 \\
\hline 11 & 58.7 & -38.7 & -17.8 & -266.3 \\
\hline 12 & 75.0 & -54.1 & -87.5 & -177.2 \\
\hline
\end{tabular}


Table 3. Load-at-failure values for maxillary molars with contracted cavity (CEC), traditional cavity (TEC) and control (intact) under continuously increasing compressive load preceded by 1 million cycles of fatiguing in the Instron Universal Testing machine.

\begin{tabular}{|c|c|c|c|}
\hline \multirow{2}{*}{ Specimen } & \multicolumn{3}{|c|}{ Load-at-failure $(\mathrm{N})$} \\
\hline & $\mathrm{CEC}$ & TEC & Control \\
\hline 1 & 1205.2 & 1246.5 & 1252.4 \\
\hline 2 & 1257.0 & 2115.5 & 3278.2 \\
\hline 3 & 3021.3 & 1452.7 & 1309.1 \\
\hline 4 & 1937.7 & 1189.3 & 1615.9 \\
\hline 5 & 1221.1 & 1264.5 & 3148.0 \\
\hline 6 & 1633.8 & 1362.3 & 2810.5 \\
\hline 7 & 1244.6 & 1286.6 & 3806.2 \\
\hline 8 & 1647.5 & 2380.6 & 3462.8 \\
\hline 9 & 1206.8 & 1387.0 & 2547.1 \\
\hline 10 & 2010.7 & 1273.9 & 2462.7 \\
\hline 11 & 1361.0 & 1321.5 & 1334.6 \\
\hline 12 & 1995.7 & 1131.1 & \\
\hline 13 & 2585.2 & 1345.8 & \\
\hline 14 & 1508.1 & 1030.7 & \\
\hline 15 & & 966.1 & \\
\hline $\min$ & 1205.2 & 966.1 & 1252.4 \\
\hline $\max$ & 3021.3 & 2380.6 & 3806.2 \\
\hline median & 1571.0 & 1286.6 & 2547.1 \\
\hline mean & 1702.5 & 1383.6 & 2457.0 \\
\hline Std Dev & 558.1 & 377.5 & 940.9 \\
\hline
\end{tabular}


Table 4. Selected diameters of V-Taper2H rotary instruments in comparison to commonly used instruments with constant taper.

\begin{tabular}{|l|c|c|c|}
\hline \multirow{2}{*}{\multicolumn{1}{|c|}{ Instrument }} & \multicolumn{3}{|c|}{ Diameter (mm) } \\
\cline { 2 - 4 } & D0 & D5 & D12 \\
\hline 20v06 V-Taper2H & 0.20 & 0.50 & 0.64 \\
20.04 Constant Taper & 0.20 & 0.40 & 0.68 \\
20.06 Constant Taper & 0.20 & 0.50 & 0.92 \\
\hline 30v06 V-Taper2H & 0.30 & 0.60 & 0.74 \\
30.04 Constant Taper & 0.30 & 0.50 & 0.78 \\
30.06 Constant Taper & 0.30 & 0.60 & 1.02 \\
\hline
\end{tabular}

